\title{
Immobilization of Chloride-Rich Radioactive Wastes Produced by Pyrochemical Operations
}

OAK RIDGE NATIONAL LABORATORY

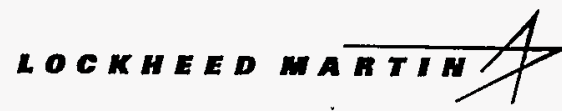

E. W. McDaniel

J. W. Terry

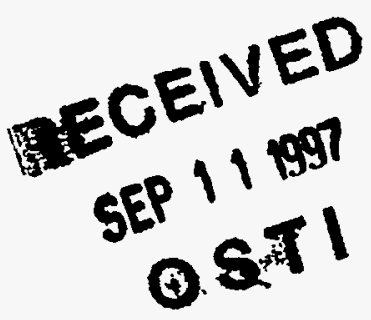

Prepared for the

U.S. Department of Energy

Assistant Secretary for Environmental Management

August 1997

Prepared by the

OAK RIDGE NATIONAL LABORATORY

Oak Ridge, Tennessee 37831

\section{Managed by}

LOCKHEED MARTIN ENERGY RESEARCH CORP.

for the

U.S. DEPARTMENT OF ENERGY

under Contract No. DE-AC05-96OR22464

MASTER

है
LOCKHEED MARTIN ENERGY RESEARCH CORPORATION FOR THE UNTED STATES DEPAPTMENT OF ENERGY 
This report has been reproduced directly from the best available copy.

Available to DOE and DOE contractors from the Office of Scientific and Technical Information, P. O. Box 62, Oak Ridge, TN 37831; prices available from (423) 576-8401, FTS 626-8401.

Available to the public from the National Technical Information Service, U.S. Department of Commerce, 5285 Port Royal Road, Springfield, VA 22161.

This report was prepared as an account of work sponsored by an agency of the United States Government. Neither the United States Government nor any agency thereof, nor any of their employees, makes any warranty, express or implied, or assumes any legal liability or responsibility for the accuracy, completeness, or usefulness of any information, apparatus, product, or process disclosed, or represents that its use would not infringe privately owned rights. Reference herein to any specific commercial product, process, or service by trade name. trademark, manufacturer, or otherwise, does not necessarily constitute or imply its endorsement, recommendation, or favoring by the United States Government or any agency thereof. The views and opinions of authors expressed herein do not necessarily state or reflect those of the United States Government of any agency thereof. 


\section{DISCLAIMER}

Portions of this document may be illegible electronic image products. Images are produced from the best available original document. 
Energy Division

\section{Immobilization of Chloride-Rich Radioactive Wastes Produced by Pyrochemical Operations}

$*_{\text {Consultant }}$

E. W. McDaniel*

J. W. Terry

Date Published-August 1997

Prepared for the

U.S. Department of Energy

Assistant Secretary for Environmental Management

Prepared by

Oak Ridge National Laboratory

Oak Ridge, Tenn. 37831-6285

managed by

Lockheed Martin Energy Research Corp.

for the

U.S. Department of Energy

under contract DE-AC05-960R22464 


\section{TABLE OF CONTENTS}

Page

ABBREVIATIONS AND ACRONYMS

EXECUTIVE SUMMARY

..v

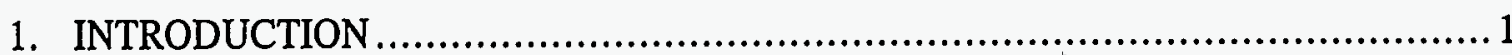

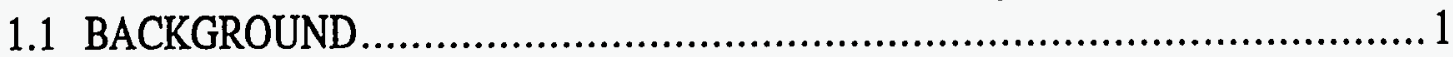

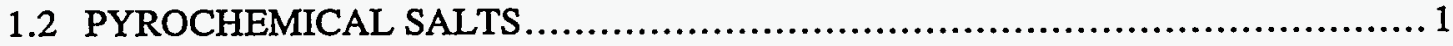

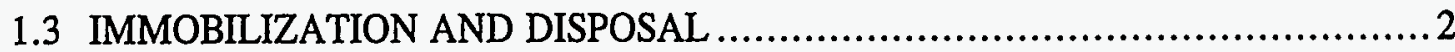

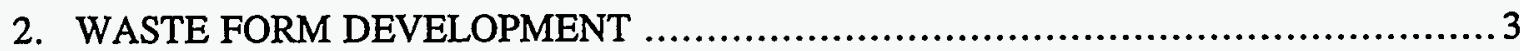

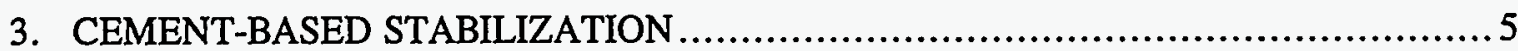

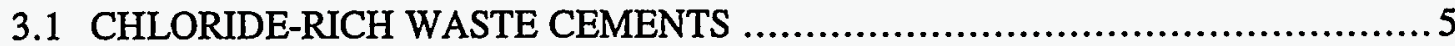

3.2 IMMOBILIZATION OF PYROCHEMICAL SALTS IN A CEMENT-BASED MATRIX............................................................... 7

3.3 CONCRETE FORMED UNDER ELEVATED TEMPERATURE

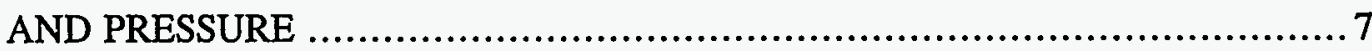

3.4 HYDROGEN GENERATION BY RADIOLYSIS IN A

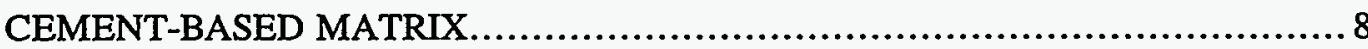

3.5 RADIATION EFFECTS ON CEMENT-BASED WASTE FORMS......................9

3.6 ADVANTAGES AND DISADVANTAGES OF CEMENT-BASED WASTE FORMS …................................................................... 10

4. LOW-TEMPERATURE VITRIFICATION OF RADIOACTIVE WASTE .................. 11

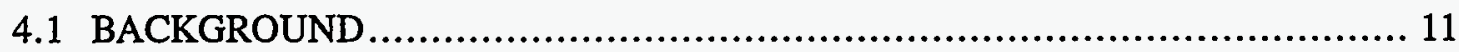

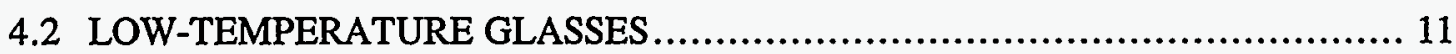

4.3 RETENTION OF CHLORINE, SULFUR, FLUORIDE AND

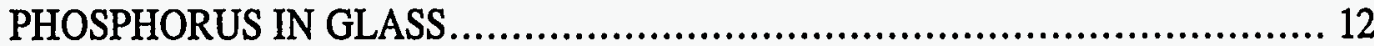

4.4 GLASS MELTER STUDIES AND OPERATIONS ..................................... 12

4.5 IMMOBILIZATION OF PYROCHEMICAL SALTS IN GLASS …............... 13

4.6 EFFECTS OF RADIOLYSIS IN GLASSES …..................................... 14

4.7 ADVANTAGES AND DISADVANTAGES OF GLASS

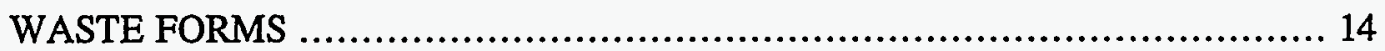

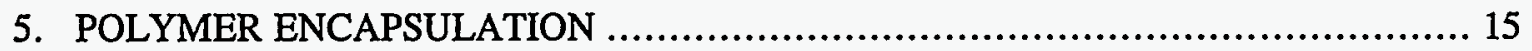

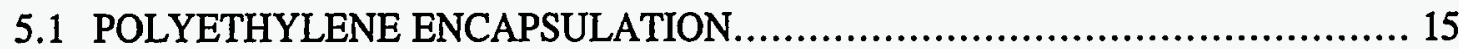

5.2 SULFUR POLYMER CEMENT ..................................................... 16

6. CONCLUSIONS AND RECOMMENDATIONS ......................................... 17

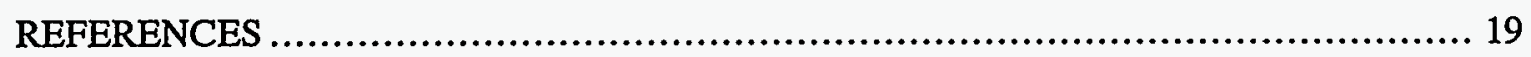

APPENDIX A. INTERIM RESIDUE CHARACTERIZATION STATUS REPORT, KAP-012-96 .....................................................

APPENDIX B. EFFECTS OF CHLORIDE IONS ON CEMENT ........................... B-1 
APPENDIX C. FLOW SHEET FOR CONCRETE FORMED UNDER ELEVATED TEMPERATURE AND PRESSURE ........................... -1

APPENDIX D. BOROSILICATE GLASS ....................................................

APPENDIX E. APPROXIMATE SOLUBILITY LIMITS FOR OXIDES OF THE ELEMENTS IN GLASS ............................................. E-1

APPENDIX F. PRIMARY DEFENSE WASTE PROCESSING FACILITY MELTER OFF-GAS SYSTEM AND MELTER DRAWINGS ................ F-1

APPENDIX G. POLYETHYLENE ENCAPSULATION PROCESS

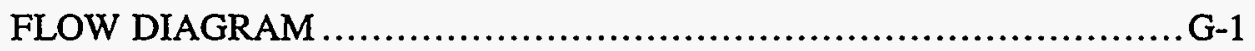

APPENDIX H. CHEMICAL COMPATIBILITY OF WASTES WITH SULFUR POLYMER CEMENT .H-1

APPENDIX I. SULFUR POLYMER ENCAPSULATION PROCESS $\mathrm{I}-1$ 


\section{ABBREVIATIONS AND ACRONYMS}

$\begin{array}{ll}\text { ANL } & \text { Argonne National Laboratory } \\ \text { BNL } & \text { Brookhaven National Laboratory } \\ \text { CH-TRU } & \text { contact handled transuranic } \\ \text { DOE } & \text { U.S. Department of Energy } \\ \text { FUETAP } & \text { formed under elevated temperature and pressure } \\ \text { HLW } & \text { high-level radioactive wastes } \\ \text { IFR } & \text { Integral Fast Reactor } \\ \text { LANL } & \text { Los Alamos National Laboratory } \\ \text { ORNL } & \text { Oak Ridge National Laboratory } \\ \text { PE-Ci } & \text { plutonium equivalent curie(s) } \\ \text { PNNL } & \text { Pacific Northwest National Laboratory } \\ \text { RFETS } & \text { Rocky Flats Environmental Technology Site } \\ \text { SPC } & \text { sulfur polymer cement } \\ \text { SRS } & \text { Savannah River Site } \\ \text { SWB } & \text { solid waste box } \\ \text { TRU } & \text { transuranic } \\ \text { VOC } & \text { volatile organic compounds } \\ \text { W/C } & \text { water to cement ratio } \\ \text { WHC } & \text { Westinghouse Hanford Company } \\ \text { WIPP } & \text { Waste Isolation Pilot Plant } \\ \text { WIPP-WAC } & \text { Waste Isolation Pilot Plant waste acceptance criteria }\end{array}$




\section{EXECUTIVE SUMMARY}

As a result of its former role as a producer of nuclear weapons components, the Rocky Flats Environmental Technology Site (RFETS), Golden, Colorado accumulated a variety of plutonium-contaminated materials. When the level of contamination exceeded a predetermined level (the economic discard limit), the materials were classified as residues rather than waste and were stored for later recovery of the plutonium. Although large quantities of residues were processed, others, primarily those more difficult to process, remain in storage at the site. The residues occur in a variety of forms with a rather broad range of plutonium concentrations.

At RFETS, it is planned for the residues with lower concentrations of plutonium to be disposed of as wastes at an appropriate disposal facility, probably the U.S. Department of Energy (DOE) Waste Isolation Pilot Plant (WIPP). Because the plutonium concentration is too high or because the physical or chemical form would be difficult to get into a form acceptable to WIPP, it may not be possible to dispose of a portion of the residues at WIPP.

The residues resulting from high-temperature processing to separate plutonium are called the pyrochemical salts. There are roughly 16 metric tons (tonnes) of pyrochemical salts at RFETS. The pyrochemical salts are among the residues that are difficult to dispose of. For a large percentage of the pyrochemical salts, safeguards controls are required. Therefore, these residues, in their present forms, cannot be disposed of at WIPP because it was not desighed to accommodate safeguards controls.

A potential solution to the safeguards controls problem for pyrochemical salt residues would be to immobilize the salts. These immobilized salts would contain substantially higher plutonium concentrations than is currently permissible but would be suitable for disposal at WIPP. This document presents the results of a review of three immobilization technologies to determine if mature technologies exist that would be suitable to immobilize pyrochemical salts: cement-based-stabilization, low-temperature vitrification, and polymer encapsulation.

This study did not find a mature technology which had been used routinely to immobilize waste streams containing high concentrations of chloride salts. Work at Argonne National Laboratory and Oak Ridge National Laboratory (ORNL), however, has shown that, on a laboratory scale, it is possible to immobilize $>30.0 \mathrm{wt} \%$ sodium chloride in a cementbased matrix. Work at ORNL and in the United Kingdom has shown that intense radiation fields decompose free water contained in the cement-based matrix into hydrogen and oxygen, thus creating a safety problem. Bench-scale tests on concrete formed under elevated temperature and pressure have shown that the potential for gas generation was reduced to near zero when free water was removed from the final waste form.

Immobilization of pyrochemical salts in low-temperature glass may be possible. The probability of gas generation from vitrified salts is near zero because of the elevated temperatures required to produce the glass and the absence of water and organic compounds in the melt formulation. The low solubility of chloride anions and plutonium cations in glass would require both glass formulation and melter development.

Polymer encapsulation by either polyethylene or sulfur polymer cement was determined to be infeasible. Polyethylene decomposes and generates gases in a radiation field. Although sulfur polymer cement shows promise, it is still in the developmental stage and little is known about long-term durability.

The authors recommend that flow sheets and life-cycle costs be developed for cementbased and low-temperature glass immobilization. An evaluation system should be developed. It is recommended that all evaluations be subjected to independent peer review. 


\section{INTRODUCTION}

\subsection{BACKGROUND}

From its founding in 1952 through the cessation of production activities in 1989, the DOE Rocky Flats Plant (now known as RFETS) located near Golden, Colorado, produced components for nuclear weapons. Some of those components were made of plutonium metal. As a result of the processes used to recover and purify plutonium and to manufacture the components, a variety of materials became contaminated with plutonium. If the level of contamination were small, the material was considered waste. However, if the concentration of plutonium in the material exceeded a predetermined level (the economic discard limit), the materials were classified as residues rather than wastes and were stored for later recovery of the plutonium. Although large quantities of residues were processed, others-primarily those more difficult to process-accumulated at the site in storage.

DOE's decision not to recover plutonium from the residues effectively turned the residues into wastes (ex-residues, now wastes, are referred to as residues in this document to differentiate them from other wastes at RFETS). To comply with an order from the State of Colorado, minimize potential exposures to workers and the public, provide a broader range of possibilities for the future uses of the site, and facilitate timely decontamination and decommissioning of buildings on the site, the residues are to be removed from RFETS.

The residues have a variety of forms and a range of plutonium concentrations. Residues with lower concentrations of plutonium will be disposed of as wastes at an appropriate disposal facility, probably the DOE Waste Isolation Pilot Plant (WIPP). Residues with plutonium concentrations that are too high or with unacceptable physical or chemical forms may not be suitable for disposal at WIPP.

\subsection{PYROCHEMICAL SALTS}

The residues resulting from high-temperature processing to separate contaminants from plutonium are called pyrochemical salts. There are roughly 16 metric tons (tonnes) of pyrochemical salts at RFETS. Eleven tonnes of these salts are composed of a sodium chloridepotassium chloride matrix. A 1982 Rocky Flats report ${ }^{1}$ described two types of molten salts used to pyrochemically remove americium from plutonium metal: an unpulverized salt consisting of sodium chloride, potassium chloride, and $8 \mathrm{wt} \%$ magnesium chloride and a pulverized salt containing $30 \mathrm{wt} \%$ magnesium chloride. Also, there is an electrorefining salt described as consisting of sodium chloride and potassium chloride with $8 \mathrm{wt} \%$ magnesium chloride. The remainder consists of a calcium chloride matrix. An additional 2 tonnes of these salt residues exists at Los Alamos National Laboratory. ${ }^{2}$

The pyrochemical salts are difficult to dispose of. For a large percentage of the pyrochemical salts, the present forms do not meet safeguards termination requirements; and the plutonium concentrations are too high for uncontrolled disposal in the present physical and chemical forms. Hence, safeguards controls are required for these residues.

Because WIPP was not designed to accommodate safeguards controls, these residues, in their present forms, cannot be disposed of there. A potential solution to the safeguards controls problem for pyrochemical salt residues would be to immobilize the salts. Immobilized salts could be disposed of at WIPP with substantially higher plutonium concentrations than are permissible for the current forms (possibly a factor of 10 higher). 


\subsection{IMMOBILIZATION AND DISPOSAL}

The purpose of this document is to determine if one or more mature technologies exist that would be suitable to immobilize the pyrochemical salts. The study assessed the maturity and suitability of cement-based stabilization, low-temperature vitrification, and polymer encapsulation. Because waste streams containing large amounts of chloride salts are not common in the nuclear industry, little work has been done by the nuclear industry to develop immobilization technologies for these wastes.

The desired technology must be mature, and must isolate the residues from moisture and ensure that the stabilized residues meet all applicable safety and waste acceptance criteria. Moisture presents two potential problems. If pyrochemical salts come in contact with moisture, there is the risk of reactive metals creating hydrogen gas which could result in pressurization and deformation of containers. Other potentially adverse reactions such as corrosion and breach of containment could occur if the untreated salts absorb sufficient moisture from the environment.

For this study, the pyrochemical salts were considered mixed, transuranic (TRU) waste (see Appendix A for characterization information). It was assumed that the stabilized (immobilized) wastes are to be disposed of at WIPP. Therefore, the immobilized pyrochemical salts must meet the WIPP waste acceptance criteria (WIPP-WAC). ${ }^{3}$ Although the WIPP-WAC do not have a specific leaching criterion, to ensure the integrity of the waste form and minimize the potential for corrosion, chloride leaching rates should be evaluated using a national standard, such as the ANS 16.1 leaching procedure. ${ }^{4}$

The safety and waste acceptance criteria used for evaluation include gas generation, potential for radiation damage, resistance to leaching, waste holding capacity, processing temperature and pressure, presence of free liquids, and sensitivity to waste chemistry. Section 3 discusses cement-based stabilization; Sect. 4 discusses low-temperature vitrification; Sect. 5 discusses polymer encapsulation; and Sect. 6 presents conclusions and recommendations. 


\section{WASTE FORM DEVELOPMENT}

To ensure the successful production of an acceptable waste form, a number of parameters must be defined or determined. A similar approach must be used for all the technologies considered and will not be repeated in the individual discussions of the waste forms. First, the waste stream must be well characterized according to an approved sampling and test plan. Second, disposal or long-term storage options must be defined. In many cases, this is coupled to a site performance assessment. Third, the regulatory requirements the waste form has to meet must be known. Fourth, it must be decided if the waste will be processed in an existing or a newly designed plant. After this information is reviewed, a series of tests can determine what materials and amounts and which mixing and process conditions are required to meet or exceed predetermined requirements. These tests must define an operating range which, if maintained, will consistently produce a waste form that meets or exceeds predetermined conditions. All work must be coupled to a well-defined quality assurance/quality control program.

In tailoring and qualifying a waste form for TRU waste immobilization, a number of criteria specific to the TRU waste must be considered. The untreated pyrochemical salts may not meet WIPP-WAC because of the plutonium concentration. Additionally, care must be taken in preparing the treated (immobilized) wastes so that the plutonium concentration criteria are not exceeded. The WIPP-WAC state that

Untreated $\mathrm{CH}-\mathrm{TRU}$ [contact handled transuranic] waste shall not exceed $80 \mathrm{PE}-\mathrm{Ci}$ [plutonium equivalent Curies] of activity per 55-gal [0.2- $\left.\mathrm{m}^{3}\right]$ drum or $130 \mathrm{PE}-\mathrm{Ci}$ per SWB [solid waste box]... 55-gal [0.2- $\mathrm{m}^{3}$ ] drums containing solidified/vitrified $\mathrm{CH}-\mathrm{TRU}$ waste shall not exceed $1800 \mathrm{PE}-\mathrm{Ci}$ of activity per drum. $^{3}$

Concentration criteria for safeguards termination on conditioned (immobilized) waste must also be met. A detailed discussion of this topic is beyond the scope of this study. With respect to mixed waste, the WIPP-WAC state that

$\mathrm{CH}$-TRU waste shall contain hazardous constituents only as co-contaminants with transuranics. All $\mathrm{CH}-\mathrm{TRU}$ mixed waste exhibiting corrosive, reactive, or ignitable characteristics shall be treated to remove the hazardous characteristic. ${ }^{3}$

For example, in the presence of moisture, the chloride salts could react with the steel drums and be considered corrosive. The immobilization process may suffice to remove the hazardous characteristics. As with safeguards termination criteria, detailed discussion of this topic is beyond the scope of this study.

Calculations must be performed to determine if there are enough PE-Ci present to generate detectable quantities of hydrogen gas. The WIPP-WAC require $100 \%$ headspace testing for hydrogen, methane, and volatile organic compounds (VOCs). Because of the process history of the salts, there is little probability of methane or VOCs being present. The immobilization process, however, may introduce water or organic compounds. 


\section{CEMENT-BASED STABILIZATION}

Cement-based immobilization, usually referred to as stabilization/solidification, is one of the most widely used methods for the treatment and disposal of both radioactive and hazardous wastes. Cementitious materials are the materials of choice in many cases because of low processing costs, compatibility with a wide variety of disposal options, and ability to meet stringent processing and performance requirements. Cementitious materials include cement (there are a large number of classes and types of cement), ground granulated blast furnace slag, fly ash (several types), and silica fume. Various clays and other admixtures are used to help immobilize contaminants or otherwise enhance the waste form properties. Most listed

cementitious materials and the equipment for mixing and transporting them are widely available and require no custom processing.

Cement-based matrices are the only matrices that can accommodate a liquid or slurry. Other immobilization technologies require that the waste be dry and in some cases, calcined (heated to a high temperature to drive off volatile components).

Cement waste-form chemistry is extremely complex and is poorly understood even for a simple system such as cement and water. The effects of any chemical species on cementwater-paste chemistry are dependent upon the matrix components, and its ability to contact the cement and, hence, interact. Waste is never a single chemical species. Usually, it is a complex mixture of a wide variety of chemical constituents, both soluble and insoluble. The chemical forms of the species of interest, the solubility of those species, and the abilities of the species to contact cement are factors complicating the waste form environment.

Conceptually, there are two broad classes of mechanisms involved in the immobilization of waste in a cement-based matrix: physical entrapment and chemical interaction. Wastes may be trapped in interstitial spaces or chemically bound to the constituents of the matrix. The capacity of the cement-based matrix to entrap or chemically bind anions, metal ions, or radionuclides may be altered by interfering species (in some cases even small amounts). If the interfering species are present in sufficient quantities, the integrity of the waste form may be jeopardized.

It is well known that admixtures can alter the properties of Portland cement. ${ }^{5}$ It is not clear whether, and in what concentrations, various waste components commonly found in waste streams interfere with the complex setting or chemical fixation reactions. Such interference may result in an altered cement-based matrix which will not adequately retain (immobilize) the waste components. The interfering reactions are environment sensitive; setting of the cement can be disrupted by waste species incorporated into the matrix. These waste species may have a particular effect for a given concentration or in a given mixture of waste species. However, for another concentration or in a different waste stream, the observed effect may be exactly the opposite.

The major disadvantage of cement-based waste forms is the substantial volume increase that occurs during immobilization. The increased volumes result in elevated transportation and disposal costs.

\subsection{CHLORIDE-RICH WASTE CEMENTS}

Typically, only a small amount of the chloride in the chloride-containing waste would be chemically fixed in the hydrates of the cement (this is the case with many waste species). The remainder of the chloride would exist as crystals embedded in the hydrate network. The porosity of the waste form would be the factor determining the leach rate. A low porosity, 
high-tortuosity matrix would help aid the retention of this ion. Many studies performed on chloride diffusion favor the hypothesis that the finer the microstructure, the smaller the diffusion of the chloride ion. ${ }^{6}$

Chloride anions can alter the amount of time it takes for the cement to set. The effect of chloride on the cement setting time depends upon the nature of the cation and the concentration of the salt (see Appendix B).

No work has been done to optimize a cement-based matrix to stabilize pyrochemical salts from plutonium operations. Possibly, the mass of radioactive materials ${ }^{239} \mathrm{Pu}$ mass equivalents), not the salt content, would determine the salt-waste loading. Studies have reported successful waste forms or cement-based matrices containing chloride loadings $>10 \mathrm{wt} \%$. Two such studies are presented below.

Stabilization of Integral Fast Reactor Salt Wastes. Chloride-rich waste solutions were generated at Argonne National Laboratory (ANL) as a byproduct of the Integral Fast Reactor (IFR) fuel cycle. Starting in 1988, ANL worked to develop a cement-based matrix (grout) to immobilize IFR salt wastes. ${ }^{7}$

Fission products in the IFR salt wastes generated heat of about $0.6 \mathrm{~W} / \mathrm{kg}$ for a mortar containing $10 \mathrm{wt} \%$ waste salt. Therefore, the effects of temperatures up to $150^{\circ} \mathrm{C}$ had to be considered. Waste loading was limited to $10 \mathrm{wt} \%$ because of heat generated by the radioactive components of the waste, not the interactions of the salt.

Two salt mixtures were used in the ANL study: (1) a combination of calcium and sodium chlorides and (2) a combination of potassium and lithium chlorides. Cement mixes with several fly ashes, sands, and clays were evaluated with respect to fluidity, setting times, and compressive strength (see Appendix B).

Tests at ANL indicated that the IFR requirements were met with a mix of about 45 wt \% Type I Portland cement, 27 wt \% class F fly ash, and 28 wt \% water; this mix contained up to $10 \mathrm{wt} \%$ salt. The ANL study concluded that up to $18 \mathrm{wt} \%$ salt in the mortar waste form was possible, but the long-term integrity of the waste form could be jeopardized by using more than $18 \mathrm{wt} \%$ salt.

There was no attempt made to optimize the waste loading of the chloride salt; the thermal properties of the waste solution were the limiting factors. Depending upon performance criteria (e.g., WIPP-WAC or U.S. Nuclear Regulatory Commission and DOE orders) a mix could be designed to exceed the $18 \mathrm{wt} \%$ salt loading reported in the ANL study.

Salt-Cement Mixes for Sealing Boreholes. Salt (typically sodium chloride)-cement mixtures or saltcretes have been widely used in the oil-well cement industry to ensure good bonding between the grouts and the sections of shale encountered in the wall of the hole. ${ }^{8}$ The addition of salt to a cement slurry used in an oil-well penetrating a salt formation is necessary to prevent the latter from being dissolved.

During the mid 1970s, work was performed at Oak Ridge National Laboratory (ORNL) to support efforts by the DOE Office of Waste Isolation to develop sealing materials for boreholes and mine shafts in potential waste disposal repository sites. ${ }^{9} \mathrm{~A}$ wide variety of cements and fly ashes were investigated in the ORNL effort. The parameters of principal interest were salt loading, setting time, and compressive strength.

Mixes with salt contents of 10,30 , and 63.2 wt \% salt were tested (see Appendix B). To permit a range of salt contents, the sand composition was varied from 0.0 to $63.2 \mathrm{wt} \%$. It was found that the cement had to be mixed with a saturated salt solution to be effective. 


\subsection{IMMOBILIZATION OF PYROCHEMICAL SALTS IN A CEMENT-BASED MATRIX}

Based on work at ORNL and ANL, it is believed that chloride-containing wastes can be immobilized successfully in a tailored, cement-based matrix exceeding $10 \mathrm{wt} \%$ chloride salts. The ANL report provides data to support waste loadings of a mixture of chloride salts up to $18 \mathrm{wt} \%$ salt. The limitations on the ANL work were thermal loading and fluidity (the mix had to be pumped). If these restrictions were removed, it might be possible to increase the waste loading. An illustrative mixture is

$\begin{array}{ll}\text { Type I Portland cement } & 23.0 \mathrm{wt} \% \\ \text { Class F fly ash } & 33.2 \mathrm{wt} \% \\ \text { Salt } & 30.0 \mathrm{wt} \% \\ \text { Water } & 13.8 \mathrm{wt} \%\end{array}$

This grout design assumes that mixing takes place in a high-shear mixer. The product is to be transferred from the mixer into the waste container in a matter of minutes.

The mix defined in the ANL study contained 2 times as much water as in the illustrative mix presented above. The $28 \mathrm{wt} \%$ water used in the ANL study was required to achieve the extended setting time and fluidity needed to permit the cement to be pumped into place. The ORNL designs, salt loadings up to $63.2 \mathrm{wt} \%$, were to be mixed and immediately put in place. Therefore, the ORNL mix could be stiffer and accommodate a higher waste loading than the ANL mix. A major concern is that mixes with such high waste loadings could experience rapid or flash setting. The occurrence of rapid or flash setting would depend upon the cation associated with the chloride anion. The setting speed could be controlled with a setting retarder.

Full scale verification would be required before the above mix design should be used. Also, the waste form must be qualified against applicable waste acceptance criteria.

In cement-based waste form development, water is necessary for cement hydration. Because water is composed of hydrogen and oxygen, the potential exists for hydrogen gas generation in the presence of an intense radiation field. This issue is addressed in Sect. 3.4.

\subsection{CONCRETE FORMED UNDER ELEVATED TEMPERATURE AND PRESSURE}

Concretes (cement-based waste forms) that are formed under elevated temperature and pressure (i.e., autoclaved) are called FUETAP concretes. The accelerated curing produces strong, durable, relatively impermeable solids. FUETAP cements or concretes typically contain some combination of the following: Portland cement, non-Portland hydraulic cement, fly ash, sand, clays, and waste products.

Laboratory studies ${ }^{10,11}$ have indicated that FUETAP concretes can be effective hosts for high-level radioactive wastes (HLW). Because the mechanical properties of FUETAP cements are superior to those of normally hardened cement pastes, making them less susceptible to weathering or degradation, they might, for that reason alone, be expected to be leach resistant (it should be noted that WIPP-WAC has no leach requirement). In addition, the investigators speculated that FUETAP's greater density and low porosity would aid in preventing radionuclides being leached from the waste form. 
The first studies were begun in the early 1970 s by D. Roy and colleagues at the Pennsylvania State University (PSU), who investigated the applicability of what they called "hot-pressed concrete" to radioactive management. Solids having a density of $2.65 \mathrm{~g} / \mathrm{cm}^{3}$ and a permeability of less than $1 \times 10^{-3}$ Darcy were made using an extremely low water to cement ratio (W/C), $0.06 \leq \mathrm{W} / \mathrm{C} \leq 0.10 \mathrm{~g} / \mathrm{g}$ (for complete cement hydration, a W/C of 0.24 is required). They used moderate temperatures $\left(150-400^{\circ} \mathrm{C}\right)$ and pressures ranging from 178 to $345 \mathrm{MPa}(25,000$ to $100,000 \mathrm{psi})$.

Since the early 1960s, extensive work to develop cement-based waste forms for the immobilization of radioactive waste has been done at ORNL. ${ }^{12}$ This experience, coupled with the encouraging results of Roy's research, led to the investigations of FUETAP at ORNL beginning in the mid-1970s. These studies differed from those of Roy in that lower temperatures and pressures $\left[250^{\circ} \mathrm{C}\right.$ and $\left.4.1 \mathrm{MPa}(600 \mathrm{psi})\right]$ were used for curing.

The purpose of the initial, generic investigation was to compare the advantages of FUETAP waste forms with existing concepts for fixation of high-specific-activity, intermediatelevel, or alpha-active wastes. It was felt that the FUETAP concept might prove suitable for HLW because the heat produced by the radioactive decay of nuclides in the incorporated wastes could be utilized in bringing the mixture to the desired $250^{\circ} \mathrm{C}$ temperature.

Studies of FUETAP concretes continued with a 4-year development program begun in the late 1970s at ORNL ${ }^{13}$ for the disposal of Savannah River Site (SRS) HLW. The work was performed using simulated SRS wastes. This work showed that only mild autoclave conditions were needed to accelerate the curing of the tailored mixtures. The work showed that curing temperature and pressure had little effect on the physical properties of cement when curing conditions were in the ranges of $100-250^{\circ} \mathrm{C}$ and $0.1-4.1 \mathrm{MPa}$. A FUETAP flow sheet is given in Appendix C. Additional tests, using sodium nitrate as the simulated waste, gave similar results.

Leach rates of the FUETAP concretes were low for transuranic radionuclides and cesium and strontium salts; the leach rates compared favorably with those from borosilicate glass. The FUETAP concretes produced were of high strength and were thermally stable to $900^{\circ} \mathrm{C}$. Radiolytic decomposition was negligible over accelerated time tests to the equivalent of 100,000 years.

\subsection{HYDROGEN GENERATION BY RADIOLYSIS IN A CEMENT-BASED MATRIX}

One of the major concerns in immobilizing large quantities of TRU waste in a cementbased matrix is the potential for pressure buildup and an explosion resulting from the accumulation of radiolytically produced gases from the decomposition of unbound or free water. One estimate of pressure buildup is that about $10.1 \mathrm{MPa}(100 \mathrm{~atm})$ could accumulate in a standard canister containing alpha waste after 100,000 years. ${ }^{14}$ However, even for this pressure, the rate of gas production would be small. For example, a standard 200-L canister containing $10 \mathrm{~g}$ of ${ }^{239} \mathrm{Pu}$ dispersed in a concrete containing normal concentrations of unbound water would generate a maximum of about $1 \mathrm{~mL}$ of hydrogen per day. Because the radiolysis of concrete is dependent on the amount of unbound or free water present in the system, removal of all or most of this water would greatly reduce this rate. The FUETAP process removes this water during the pressurized cure period.

Regardless of the hydrogen production rate, pressurization from the accumulation of hydrogen and oxygen would be avoided if there were sufficient recombination of these gases

during or after their generation. Based upon this assumption, work was undertaken at ORNL ${ }^{15}$ to determine if the addition of a catalysis would, under laboratory conditions, serve to 
recombine hydrogen and oxygen that resulted from the radiolytic decomposition of free water in a cured but not de-watered FUETAP waste form.

The ORNL work showed in a series of three experiments that there is a high hydrogenoxygen recombination rate in the presence of FUETAP concretes containing simulated waste. Ferric oxide was used as the catalyst. Gas recombination was compared with a sample containing a comparable amount of aluminum oxide which is considered inert. The work showed that a $300 \mathrm{~g}$ sample will catalyze the recombination of greater than $8 \mathrm{~mL}$ of hydrogen per day. The ORNL reports concluded that radiolytic gas generation may not be a problem with FUETAP (assuming proper tailoring) concretes containing waste provided that adequate contact is maintained between the gases and the available solid surfaces. ${ }^{15}$ It should be remembered that the ORNL conclusions are based on a series of three laboratory tests.

Because of the selection of borosilicate glass as the immobilization matrix for HLW only one engineering scale experiment was run. There are no data available on this work. Also, there were no process flow sheets developed. The flow sheet would consist of three parts:

(1) Cement handling, mixing, and transport. The cement and concrete industry is well established; the required equipment is mature and readily available at reasonable cost. (2) Pressure vessel. As FUETAP is a relatively low temperature and pressure process, a number of commercial autoclaves (or pressure cookers) are available. (3) Dewatering. Dewatering would be a simple operation consisting of a means to remove the excess water under a vacuum prior to cooling and removal from the pressure vessel.

\subsection{RADIATION EFFECTS ON CEMENT-BASED WASTE FORMS}

Cements and concretes are generally regarded as resistant to radiation levels up to $10^{8}$ rads. ${ }^{16}$ Beyond that, deterioration of properties, particularly strength occurs.

Before the early 1980 s, there was little information about the effects of radiation on cement-based matrices. Beginning in 1981 and continuing through 1985, extensive studies were conducted on this subject in the United Kingdom. ${ }^{17}$ Discussion in this section reflects the UK work.

Radiation can affect cement materials in two ways. First, atoms can be displaced from their normal sites. In crystalline solids (waste forms), this could lead to a volume increase. In glasses or other non-crystalline solids, increased atomic mobility may nucleate crystallization, again with a volume change. If the solid phases in a cement-base monolith are affected in this way, disruptions of the microstructure could occur. Atomic displacements usually result from heavy particle radiation, such as neutrons or alpha decays.

The other mechanism by which radiation may influence the properties of waste forms arises from radiolysis of the aqueous phase within hydrated cement. As noted in Sect. 3.4, radiolysis of the aqueous phase would result from all forms of ionizing radiation. Reactive species would be produced as free radicals which could react to disrupt the microstructure of the monolith.

It is likely that observable effects of radiation, particularly the detection of radiolytically produced gases, would always be associated with a cement-based matrix used to immobilize radioactive wastes. The UK work did not, however, show a significant effect on the solid phase microstructure of the cement or concrete, and hence on its macroscopic properties. ${ }^{17}$ 


\subsection{ADVANTAGES AND DISADVANTAGES OF CEMENT-BASED WASTE FORMS}

The advantages to cement-based waste forms include the following: resistance to radiation damage, acceptable leaching rates for alpha-, beta-, and gamma-emitting nuclides, acceptable waste loading, low-temperature processing (FUETAP cement processing at $250^{\circ} \mathrm{C}$ is low temperature), absence of free liquids, chemically stable product, thermally stable waste form, adequate compressive strength, and widely available materials requiring no custom processing. A significant advantage of cement-based immobilization is that the waste stream requires little or no pretreatment. The process can accommodate liquids, sludges, and dry materials.

The disadvantages to cement-based waste forms include the following: gas generation (minimal for FUETAP concrete), unknown chloride anion leaching rates, steam pressurization (for FUETAP concrete), required off-gas system (for FUETAP concrete), possibly rapid setting, and higher transportation and disposal costs as a result of increased volume.

Depending upon the waste stream, there may be additional advantages and disadvantages of using a cement-based waste form. The advantages and disadvantages listed above apply primarily to immobilization of pyrochemical salts. In selecting borosilicate glass as the waste form of choice for HLW, the DOE evaluated seven candidate waste forms. FUETAP concrete ranked fifth. ${ }^{18}$

Cement-based immobilization is considered mature technology. In recent years, a number of problems in the use of cement-based waste forms have been found at DOE sites. ${ }^{19}$ Most of the reported problems were the result of improper tailoring and inadequate quality assurance and quality control.

FUETAP concrete must be considered experimental. Before this process could be used to immobilize the pyrochemical salts, a mix would have to be designed for the chloridecontaining wastes and the properties of the resulting concrete would have to be demonstrated on an engineering scale. 


\section{LOW-TEMPERATURE VITRIFICATION OF RADIOACTIVE WASTE}

\subsection{BACKGROUND}

As in cement-based waste immobilization technology, tailoring to specific requirements is also necessary in developing a vitreous matrix to sequester radioactive and hazardous species. When vitrification is mentioned, it is usually assumed to refer to HLW and borosilicate glass. Borosilicate glass vitrification is a rather high-temperature $\left(1200-1600^{\circ} \mathrm{C}\right)$ process (see Appendix $\mathrm{D}$ for additional details on borosilicate glass). However, there are other glasses of interest that are referred as low-temperature glasses. This section will focus on the lowtemperature glasses.

Four general points are important to any discussion of vitrification. First, glass is a supercooled liquid which for all practical purposes is a solid at room temperature. However, in the strict physical sense, at room temperature, glass is a liquid that is so viscous that it has the characteristics of a solid. However, it does not have any crystalline phases which define a solid. Second, immobilization of waste in a glass matrix requires that the oxide be soluble in the chosen matrix. Most oxides of interest in nuclear waste management have limited solubilities in tailored glass (see Appendix E). For instance, the solubility of plutonium oxide is only $3.0 \mathrm{wt} \%$ in glass, whereas the solubility of lead oxide is $30.0 \mathrm{wt} \%$.

Third, anions are not usually considered for immobilization in glass. Even in low-temperature glasses $\left(<1200^{\circ} \mathrm{C}\right)$, nitrates decompose and sulfates froth and foam. Chlorides all have high vapor pressures and tend to volatilize at glass melter temperatures. Fourth, even though most glass matrices melt at $400-600^{\circ} \mathrm{C}$, the melt must be thin enough for the respective waste compounds to be dispersed in the fluid rather than float on the surface.

Vitrification can be accomplished by a wide variety of processes. These include fossil fuel combustion, Joule (electric) heating, plasma arc melting, graphite arc melting, in situ vitrification, and induction and microwave heating. The choice of a melter will depend upon the characteristics and requirements of a specific waste stream. Information about a low-temperature, low-level or TRU waste glass melter is not available. However, for illustrative purposes, a flow sheet of the SRS Defense Waste Processing Facility (an HLW facility) and a melter schematic are given in Appendix F.

\subsection{LOW-TEMPERATURE GLASSES}

A number of efforts have investigated other glass compositions such as phosphate, soda-lime-silica, and aluminosilicate glasses for waste solidification. In the United States, these efforts were abandoned in favor of borosilicate glass. However, the former Soviet Union continued to develop phosphate glasses. ${ }^{20,21}$

Attempts to immobilize HLW in a glass matrix were made in the 1960s using phosphate-based glasses. Phosphate glasses offered several advantages relative to silicate-based glasses. Phosphate glasses required a lower melting temperature and had a higher solubility for sulfates..$^{22}$ In earlier attempts with sodium phosphate glass melts, it was discovered that these melts were extremely corrosive and must be melted in platinum-lined melters. In addition, these glasses tended to be susceptible to devitrification, which resulted in the formation of phases with chemical durabilities which were lower than that of the parent glass. Unfortunately, as the result of problems with the sodium phosphate glasses, work in the United States on all other 
phosphate waste forms for HLW was discontinued after about 1972. However, work continued in Europe on the development of phosphate glasses for HLW. ${ }^{23,24}$

Lead-iron phosphate (LIP) glasses were developed at ORNL in $1984^{25}$ and are reported to be corrosion resistant in aqueous solutions at temperatures below $100^{\circ} \mathrm{C}$. These glasses can be melted and poured at temperatures that are relatively low in comparison to borosilicate glass. The LIP glasses are not nearly as corrosive as sodium phosphate glasses. Therefore, these glasses can be melted and processed in a wide variety of materials.

The chemistry and structural properties of LIP glasses are dominated by the relative concentrations of phosphorous pentoxide, lead oxide and iron (ferric) oxide. Lead oxide is added primarily to lower both the preparation temperature and the melt viscosity. Iron oxide is added to improve the chemical durability of the glass and to suppress the tendency to crystallize. Also the properties of LIP glasses can be tailored for a particular application.

LIP glasses have been prepared only on a laboratory scale using simulated defense wastes. The study showed that all of the waste oxides and silicates contained in both simulated U.S. defense waste and simulated commercial waste were completely dissolved in the melt at $1050^{\circ} \mathrm{C}$. Waste loading was reported as $0.73 \mathrm{~g} / \mathrm{cm}^{3}$ or about $6.0 \mathrm{wt} \%$.

During fiscal years 1994 through 1995, both Brookhaven National Laboratory (BNL) and Pacific Northwest National Laboratory (PNNL) provided technical support to Westinghouse Hanford Company (WHC) in its efforts to develop a glass for vitrification of low-level tank waste. ${ }^{26}$ Preliminary tests were performed on several combinations of aluminum oxide, ferric oxide, and phosphorous pentoxide glasses. The mix was melted for 3-5 hr at $900^{\circ} \mathrm{C}$ and annealed for $1-2 \mathrm{hr}$ at $350-390^{\circ} \mathrm{C}$. No surrogate waste was immobilized. The preliminary work was conducted to obtain glass formation and determine stability. The program was canceled at the end of fiscal year 1995 when DOE decided to privatize tank waste efforts at the Hanford Site.

\subsection{RETENTION OF CHLORINE, SULFUR, FLUORIDE AND PHOSPHORUS IN GLASS}

In support of the Hanford tank waste vitrification program, PNNL evaluated a number of glasses for their ability to retain chlorine, sulfur, fluorine, and phosphorus. ${ }^{27}$ Although the glass formulations cannot be considered low temperature, the PNNL findings are worth noting. Melting was in the range of 1140 to $1400^{\circ} \mathrm{C}$, only marginally within the $<1200^{\circ} \mathrm{C}$ typically stated for low-temperature glasses. Glasses containing $9.0 \mathrm{wt} \%$ calcium oxide and no boron dissolved $1.01 \mathrm{wt} \%$ sulfur; glasses containing $2.0 \mathrm{wt} \%$ or less calcium oxide retained $0.63 \mathrm{wt} \%$ fluorine. Glass melted at $1130^{\circ} \mathrm{C}$ dissolved $0.5 \mathrm{wt} \%$ chlorine. Fluorine retention was found to be a function of calcium oxide content. PNNL concluded that chlorine retention was a function of temperature and not of glass composition.

\subsection{GLASS MELTER STUDIES AND OPERATIONS}

There are no state-of the-art glass melters commercially available. It is common practice to develop a melter and prove it in pilot plant operations prior to design and construction of a production melter. This process is expensive and requires a lengthy development period. 
An example of the lengthy, expensive development process is the multi-phase melter systems technology demonstration, testing, and evaluation program carried out by WHC during fiscal years 1993-1995. 28,29,30 A detailed discussion of the WHC program is beyond the scope of this study. However, a brief discussion serves to illuminate two salient points: (1) the melter was developed for a specific waste type and (2) there were several competing melter types and configurations.

The purpose of the WHC program was to identify the best overall melter-system technology available for vitrification of Hanford Site low-level wastes. Phase I was a "proof-ofprinciple" test to demonstrate that a melter system could process a simulated highly alkaline, high-nitrate waste and produce a product of consistent quality.

Four melter types from seven melter vendors were selected for evaluation. The melter types and associated vendors are (1) Joule-heated melters from Duratek, Envitco, Penberthy Electromelt, and Vectra Technologies; (2) a gas-fired cyclone burner from Babcock \& Wilcox; (3) a plasma torch fired, cupola furnace from Westinghouse Science and Technology Center; and (4) an electric-arc furnace with top-entering vertical-carbon electrodes from the U.S. Bureau of Mines.

When Phase I was completed, the results were to remain confidential until the second phase was completed. Phase II was discontinued because of the new direction taken by the DOE to privatize tank-waste treatment activities. Some of the Phase I information has been released, ${ }^{31,32,33}$ but was not reviewed for this study.

All melter development has not been inconclusive. There are a number of melters operating successfully in the world today. There are two in France and one in the UK. These melters vitrify HLW waste that results from processing spent fuel elements. In the United States, there is a melter at the West Valley Demonstration Project, West Valley, New York and a melter at the Defense Waste Processing Facility, SRS, Aiken, South Carolina. These melters also process HLW from fuel reprocessing. All these melters underwent a lengthy development stage prior to becoming operational.

\subsection{IMMOBILIZATION OF PYROCHEMICAL SALTS IN GLASS}

The pyrochemical salts in question are unique to plutonium processing. Little treatment and immobilization efforts are reported in the open literature. The Japanese report work done at the Tokai Research Center and Central Research Institute for Electric Power Industry. ${ }^{34}$ They have been developing a pyrometallurigical process to separate TRU elements from highly active waste. The intent is to transmute the TRU isotopes into short-lived nuclides in a metallicfuel fast-breeder reactor. A chloride waste consisting of sodium chloride and lithium chloride containing short-lived fission product chlorides arises from the reductive extraction process and electrorefining. The lithium is recovered by electro-reduction and reused. The chloride is converted to chlorine gas, recovered, and reused. The slag is immobilized in borosilicate glass. On the basis of the Japanese work, coupled with the fact that chlorides are volatile at glass melting temperatures, low-temperature glass may be a better option for immobilizing pyrochemical salts than borosilicate glass. However, the low solubility of chloride anions and plutonium cations in glass would require both glass formulation and melter development. 


\subsection{EFFECTS OF RADIOLYSIS IN GLASSES}

Vitrified waste forms contain extremely small quantities of water or other sources of gases. Hence, the potential for radiolytic gas generation is very near zero.

Even though there are no data on low-melting glasses with respect to radiation damage, a wealth of data is available on borosilicate glasses. Studies, including specimens doped with ${ }^{238} \mathrm{Pu}$ and ${ }^{244} \mathrm{Cm}$, indicate that the performance of waste glass should not be affected significantly by self-irradiation at design concentrations of actinides for periods of 1 million years or more. ${ }^{35}$

\subsection{ADVANTAGES AND DISADVANTAGES OF GLASS WASTE FORMS}

The advantages of low-temperature glass waste forms include the following: very low gas generation rate, resistance to radiation damage; substantial leaching resistance, lowpressure processing, absence of free liquids, chemical durability, physical durability, biological durability, flexible composition, and high compressive strength.

The disadvantages of low-temperature glass waste forms include the following: low solubility for certain elements, limitations on metals in feed, incompatibility between the waste stream and the melter, high temperature processing, off-gas system required, limited experience with wastes other than HLW, extensive maintenance required, and disposal of spent vitrification unit. 


\section{POLYMER ENCAPSULATION}

A number of polymers or organic binders have been used in the nuclear utilities industry to encapsulate a variety of low-level wastes. Most dry waste streams can be encapsulated because the process is one of physical encapsulation and not chemical combination or dissolution as is the case with cement and glass. Some examples of organic binders are bitumen and polyethylene which are referred to as thermoplastic. Other organic binders are vinyl ester styrene and epoxies; these are referred to as thermosetting. Sulfur polymer cement (SPC) is an inorganic binder. Polyethylene and SPC are discussed below. Bitumen and vinyl ester styrene are not considered appropriate immobilization technologies for pyrochemical salts because of the potential for fire and the hazardous nature of some chemicals associated with vinyl ester styrene encapsulation. Significant work has been done at BNL on the encapsulation of sodium nitrate salts in thermoplastics. ${ }^{36}$

\subsection{POLYETHYLENE ENCAPSULATION}

A polyethylene encapsulation system has been developed by BNL for the treatment of low-level radioactive, hazardous, and mixed waste. ${ }^{37}$ The BNL report lists several advantages compared with conventional solidification/stabilization materials such as hydraulic cements. However, the long-term durability of and disposal environment required for polyethylene are not as well defined and documented as for cement-based systems.

Polyethylene has been successfully used both at RFETS and SRS to incorporate sodium nitrate wastes. Waste loading in the range of $70 \mathrm{wt} \%$ have been achieved. The BNL report also reported successful encapsulation of calcium, sodium, potassium, and magnesium chlorides in polyethylene. An encapsulation process flow diagram is given in Appendix G.

Effects of Radiolysis on Polyethylene. Studies of gas evolution from polyethylene irradiated in the absence of air indicated yields of hydrogen, methane, ethane, propane, butane and other hydrocarbon gases. The extent to which the polyethylene encapsulation is damaged upon intensive irradiation is not well documented. It is anticipated that the effect may be substantial.

Advantages and Disadvantages of Polyethylene Encapsulation. The advantages of polyethylene encapsulation include the following: insensitivity to waste chemistry, low-pressure processing, absence of free liquids, no chemical reactions required for solidification, compatible with chlorides, broad range of molecular weights from which to choose feed stock, and easily reworked. The disadvantages of polyethylene encapsulation include the following: gas generation in radiation fields, substantial potential for radiation damage, unknown leaching rate, high-temperature process $\left(>350^{\circ} \mathrm{C}\right)$, waste must be dried prior to encapsulation $(<2 \mathrm{wt}$ $\%$ water), potential for foaming, no stability information, and limited processing experience. The disadvantages of polyethylene encapsulation outweigh the advantages. The safety and radiation damage concerns combined with the limited processing experience overwhelm chemical compatibility. 


\subsection{SULFUR POLYMER CEMENT}

SPC was developed in 1985 at BNL as an encapsulation media for low-level, hazardous, and mixed waste. ${ }^{38}$ As a relativity new material, SPC's long-term durability has not been proven, even though some materials have been found to resist a highly corrosive environment for over 9 years. ${ }^{39}$

The development and testing of SPC by the U.S. Bureau of Mines and the tests conducted by universities, states, and the concrete industry during the past two decades have been promising. The ability of SPC to withstand attacks by most acids and salts that have destroyed Portland cement-based concretes has offered evidence that SPC might perform better at stabilizing waste than a cement-based matrix. Additionally SPC is compatible with many chemicals, including chlorides (see Appendix $\mathrm{H}$ for a list of chemicals compatible with SPC) SPC. However, tests are necessary to determine if the SPC can accommodate reasonable loadings of radioactive and/or hazardous waste and still provide adequate stabilization.

Two problems were noted with using elemental sulfur as a cement: as it cooled and hardened, it lacked mechanical strength and shrank too much. These problems were caused by changes occurring in the crystalline structure during cooling. ${ }^{40}$ These problems were solved by the addition of a mixture of dicyclopentadiene and the oligamers of cyclopentadiene in equal quantities totaling $5 \mathrm{wt} \%$ of the sulfur.

In the field of immobilization of low-level or mixed waste, this process is still in the development stage. ${ }^{40}$ No data exist on its long-term durability despite predictions by some that the durability of SPC could be twice that of Portland cement-based systems. ${ }^{40}$ A sulfur polymer encapsulation process flow diagram is given in Appendix I. Because of the developmental nature of SPC, it is not considered as a candidate waste form for pyrochemical salts.

Gas Evolution from Radiolysis of Sulfur Polymer Cement. Water is not present in the sulfur or additives required to prepare SPC. However, the required additives are organic compounds. The addition of organic compounds in the amount of $5 \mathrm{wt} \%$ would result in about $4.5 \mathrm{~kg}(10 \mathrm{lb})$ of organic compounds in a $0.2-\mathrm{m}^{3}(55$-gal) drum of solidified waste. In a radiation field, the risk of gas generation is great. This uncertainty alone is enough to require much product testing and evaluation.

Advantages and Disadvantages of Encapsulation in Sulfur Polymer Cement. The advantages of sulfur polymer cement encapsulation are the following: low leaching rate, lowpressure processing, absence of free liquids, compatibility with chlorides, compatibility with many wastes, resistant to many chemicals, rapid hardening (also a potential disadvantage), assured solidification, and easy rework. The disadvantages of sulfur polymer cement encapsulation are the following: gas generation in radiation fields, potential for radiation damage (destruction of organic components), unknown capacity for radioactive and hazardous wastes, high-temperature process, poor compatibility with alkaline solutions, deformation at $>90^{\circ} \mathrm{C}$, absence of long-term durability data, waste feed dried to $<1$ wt \% water, preheated waste feed, off-gas scrubber required, and limited processing experience. Although the disadvantages of sulfur polymer cement encapsulation are similar to those of polyethylene encapsulation, the magnitude of the disadvantages is smaller for sulfur polymer cement. Additional experimentation and processing may establish sulfur polymer cement encapsulation as a viable alternative to cement-based encapsulation or low-temperature vitrification. 


\section{CONCLUSIONS AND RECOMMENDATIONS}

This study concludes that no mature technology has been used routinely to immobilize waste streams containing high concentrations of chloride salts. Work at ANL and ORNL has shown that on a laboratory scale it is possible to immobilize $>30.0 \mathrm{wt} \%$ sodium chloride in a cement-based matrix. Work at ORNL and in the UK has shown that intense radiation fields decompose free water contained in the cement-based matrix into hydrogen and oxygen, thus creating a safety problem. Bench-scale tests on FUETAP concrete have shown that when free water was removed from the final waste form, the potential for gas generation was eliminated.

Immobilization of pyrochemical salts in low-temperature glass may be possible. The low solubility of chloride and plutonium in glass would require both glass formulation and melter development.

Other immobilization technologies reviewed in this study were polyethylene and SPC. Both were rejected. Polyethylene is susceptible to decomposition and gas generation in radiation fields, and sulfur polymer cement is still a developing technology.

It is recommended that flow sheets and life cycle costs be developed for a cement-based matrix and a low temperature glass process. A figure-of-merit system of evaluation similar to that used in selecting borosilicate glass for $\mathrm{HLW}^{41}$ should be developed. It is recommended strongly that all formulation and process development be given very close, independent peer review. 



\section{REFERENCES}

1. Luckett, L. L., History of Rocky Flats Waste Streams, RFP-3186, U.S. Department of Energy, Rocky Flats Plant, Mar. 1982.

2. U.S. Department of Energy, Plutonium Focus Area, Technology Summary, DOE/EM-0297, Aug. 1996.

3. U.S. Department of Energy, Waste Acceptance Criteria for the Waste Isolation Pilot Plant, DOE/WIPP-069, rev. 5, Apr. 1996.

4. Measurement of the Leachability of Solidified Low-Level Radioactive Wastes, Draft, American Nuclear Society Standards Committee, Working Group ANS 16.1 Washington, D.C., Feb. 1986.

5. Ramachandran, V. S., ed., Concrete Admixtures Handbook, Noyes Publications, Park Ridge, N.J., 1984

6. Glasser, F. P., "Progress in the Immobilization of Radioactive Wastes in Cement" in Cement and Concrete Research, 22:201-16 (1992).

7. Fischer, D. F. and Johnson, T. R., "Immobilization of IFR Salt Wastes in Mortar," Proceedings of The International Topical Meeting on Nuclear and Hazardous Waste Management Spectrum 88, Sept.11-15, 1988, Pasco, Wash.

8. Smith, D. K., Cementing, Society of Petroleum Engineers of AIME, 1976.

9. Moore, J. G., Morgan, M. T., McDaniel, E. W., Cement Technology for Plugging Boreholes in Radioactive Waste Repository Sites: Progress Report for the Period October 1, 1977 to September 30, 1978, ORNL-5524, Oak Ridge National Laboratory, Oak Ridge, Tenn., 1979.

10. Roy, D. M., and Gouda, G. R., Nuclear Technology. 40:214 (1978).

11. Moore, J. G., Newman, E. and Rogers, G. C., Radioactive Waste Fixation in FUETAP (Formed Under Elevated Temperature and Pressure) Concretes-Experimental Program and Initial Results, ORNL/TM-6573, Oak Ridge National Laboratory, Oak Ridge, Tenn., 1979.

12. DeLaguna, W. T., Tamura, T., Weeren, H. O., Struxness, E. G., McClain, W. C., and Sexton, R. C., Engineering Development of Hydraulic Fracturing as a Method for Permanent Disposal of Radioactive Wastes, ORNL-4259, Oak Ridge National Laboratory, Oak Ridge, Tenn., 1968.

13. Dole, L., Rogers, G., Morgan, M., Stinton, D., Kessler, J., Robinson, S. Moore, J., Cement-Based Radioactive Waste Hosts Formed Under Elevated Temperature and Pressures (FUETAP Concrete) for Savannah River Plant High-Level Defense Waste, ORNL/TM-8579, Oak Ridge National Laboratory, Oak Ridge, Tenn., 1983.

14. Bibler, N. E., U.S. Department of Energy, Savannah River Site, SRL-DP-1464, Jan. 1978.

15. Katz, S., "The Reaction of Hydrogen and Oxygen in the Presence of Concretes by Incorporating Simulated Radioactive Waste," Scientific Basis for Nuclear Waste Management, vol. 2, C. Northrup, ed., Plenum Press, 1980.

16. 10 CFR Part 61.

17. Phillips, D. C., McHugh, G., Hitchon, J. W., Willing, C. R., Spindler, W. E., Lyon, C. E., Winter, J. A., and Lindswell, P. H. R., The Effects of Radiation on Intermediate-Level Waste Forms, AERE-R 13019, 1988.

18. U.S. Department of Energy, The Evaluation And Selection Of Candidate High-Leiel Waste Forms, DOE/TIC 11611, Mar. 1982. 
19. Lomenick, T. F., Proceedings of the Workshop on Radioactive, Hazardous, and/or Mixed Waste Sludge Management, December 4-6, 1990, Knoxville Tenn., CONF-901264, U.S. Department of Energy, Oak Ridge K-25 Site, Oak Ridge, Tenn. 1990.

20. Demin, A. V., Matyunin, Yu. I., Polyakov, A. S., and Fedorova, M. I., "Study of highlevel liquid waste component behavior during solidification to produce phosphate and borosilicate vitreous materials," pp. 435-441 in Proceedings of the 1993 International Conference on Nuclear Waste Management and Environmental Remediation. Volume 1: Low and Intermediate Level Radioactive Waste Management, D. Alexandre, R. Baker, R. Kohout, and J. Marek, eds., American Society of Mechanical Engineers, 1993.

21. Matyunin, Yu. I., Demin, A. V., Teterin, E. G., "A Study of the Behavior of Uranium, Plutonium, and Radiogenic Americium upon Vitrification of Model High-Level Liquid Wastes," in Glass Physics and Chemistry, 21: $432-438$ (1995).

22. Lutze, W. and Ewing, R. C., eds., Radioactive Waste Forms For The Future, NorthHolland, New York, 1988.

23. Pascual, L. and Duran, A., "Nitridation of glasses in the system $\mathrm{R}_{2} \mathrm{O}-\mathrm{MO}-\mathrm{P}_{2} \mathrm{O}_{5}$," in Materials Research Bulletin, 31: 77-95 (1996).

24. Simon, V., Ardelean, I., Cozar, O., and Simon, S., "Valence States of Uranium and Gamma Irradiation Defects in Soda-Phosphate Glasses," in Journal of Materials Science Letters, 15: 784-785 (1996)

25. Sales, B. C. and Boatner, L. A., "Lead-Iron Phosphate Glass," Chap. 3 in Radioactive Waste Forms for the Future, W. Lutze and R. C. Ewing, eds., Elsevier Science Publishers, 1988.

26. One of the authors served as consultant to Westinghouse Hanford Corporation during this period.

27. Feng, X., Schweiger, M. J., Li, H., and Gong, M., “ Retention of Sulfur, Phosphorus, Chlorine, and Fluorine in Hanford Phase II Vendor LLW Glasses," p. 555 in Proceedings of Spectrum-96, Aug. 18-23, 1996, Seattle, Wash., American Nuclear Society, LaGrange Park, Ill.

28. Hendrickson, D.W., Hanford Low-Level Vitrification Melter Testing - Master List of Data Submittals, WHC-SD-WM-ML-001, Westinghouse Hanford Co., Richland, Wash., Mar. 1995.

29. Wilson, C.N., Burgard, K.C., Weber, E.T., Brown, N.R., Melter Technology Evaluation for Vitrification of Hanford Site Low-Level Waste, WHC-SA-2857, Westinghouse Hanford Co., Richland, Wash., Apr. 1995.

30. Higley, B.A., Test Plan for Glass Melter System Technologies for Vitrification of HighSodium Content Low-Level Radioactivity Liquid Waste, WHC-SD-WM-VI-018, Westinghouse Hanford Co., Richland, Wash., Mar. 1995.

31. Eaton, W.C., Oden, L.L., O'Connor, W.K., U.S. Bureau of Mines, Phase 1 Hanford LowLevel Waste Melter Tests: Final Report, WHC-SD-WM-VI-030, Westinghouse Hanford Co., Richland, Wash., Nov. 1995.

32. Eaton, W.C., GTS Duratek, Phase I Hanford Low-Level Waste Melter Tests: Final Report, WHC-SD-WM-VI-027, Westinghouse Hanford Co., Richland, Wash., Oct. 1995.

33. Stegen, G.E., Wilson, C.N., Vectra GSI, Inc., Low-Level Waste Melter Testing Phase I Test Report, WHC-SD-WM-VI-031, Westinghouse Hanford Co., Richland, Wash., Feb. 1996.

34. Tadashi, I., Sakata, M., and Kania, T., "Treatment of Molten Chloride Waste from Pyrometallurigical Process," p. 775 in Proceedings of Waste Management 94, vol.1, R. Post and M. Wacks, eds,. Tucson, Ariz., Feb. 27-March 3, 1994. 
35. Roberts, F. P., Turcotte, R. P., and Weber, W., Materials Characterization Center Workshop on the Irradiation Effects in Nuclear Waste Forms-Summary Report, PNL-3588, Pacific Northwest Laboratory, Richland, Wash., Jan. 1981.

36. Adams, J. W. and Kalb, P. D., "Thermoplastic Stabilization Treatability Study for a Chloride, Sulfate and Nitrate Salts Mixed Waste Surrogate," in Emerging Technologies in Hazardous Waste Management VI, D. W. Tedder and R. G. Pohland, eds., American Academy of Environmental Engineers, 1996.

37. Kalb, P. D., Heiser, J. H., III, and Colombo, P., Polyethylene Encapsulation of Nitrate Salt Wastes: Waste Form Stability, Process Scale-up and Economics, BNL-52293, Brookhaven National Laboratory, Upton, N.Y., 1991.

38. Arnold, G., et. al., Modified Sulfur Solidification of Low-Level Wastes, BNL-51923, Brookhaven National Laboratory, Upton, N.Y., 1985.

39. Darnell, G. R., "Sulphur Polymer Cement, a New Stabilization Agent for Mixed and LowLevel Radioactive Wastes," pp 7.1.1-7.1.11 in Proceedings of the First International Symposium on Mixed Waste, Baltimore, Md., Aug. 26-29, 1991, A. A. Moghissi and G.A. Benda, eds., Univ. of Maryland, Baltimore, 1991.

40. U.S. Department of Energy, Mixed and Low-Level Treatment Facility Project, Vol. 3: Waste Treatment Technologies, EGG-WMO-10244, Idaho National Engineering Laboratories, Idaho Falls, Id., Apr. 1992.

41. U.S. Department of Energy, The Evaluation And Selection Of Candidate High-Level Waste Forms, DOE/TIC 11611, Mar. 1982. 


\section{APPENDIX A}

INTERIM RESTDUE CHARACTERIZATION STATUS REPORT

KAP-012-96 


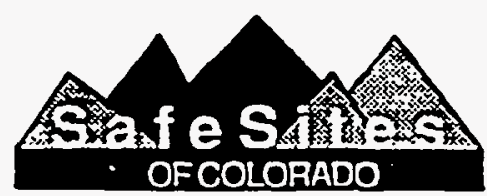

\title{
INTEROFFICE CORRESPONDENCE
}

\author{
DATE: July 22, 1996 \\ TO: $\quad$ Jeanne Ball, SSOC, Residue Stabilization, Bldg. 441, X5123
FROM: $\quad$ Karen Phillips, SSOC, Residue Stabilization, Bldg. T883A, X3612 \\ SUBJECT: INTERIM RESIDUE CHARACTERIZATION STATUS REPORT KAP-012-96
}

\begin{abstract}
The purpose of this memorandum is to provide interim status of the residue characterization project. The report summarizes the analytical results received to date. as well as the observations recorded on those containers during sampling. As the statistical sampling for item description code (IDC) populations is completed. a separate, more detailed report will be issued. The reports will include the raw data and photographs as attachments. Headspace gas sampling results are not included in this report and will be compiled in a separate report.
\end{abstract}

Although not counted towards the Kaiser Hill FY96 performance measure, the containers sampled prior to this fiscal year are also included. The characterization results of the six containers sampled prior to FY96 comprise section 1.0. Section 2.0 lists the residue containers that have been sampled this fiscal year and provides a top-level summary of the characterization results. The detailed characterization summaries of the containers completely analyzed are contained in section 3.0.

\subsection{BACKGROUND}

Prior to this fiscal year. limited residue sampling was conducted. Three IDC 411 electrorefining (ER) satt cans were sampled in September 1994. Prior to this effort, only headspace gas sampling of residue drums had been conducted. The headspace gas sampling revealed a slight glimpse on how the Rocky Flats residues were behaving during storage. Specifically, high hydrogen was unexpectantly present in residue IDCs like pyrochemical salts, materials thought to be innocuous in regard to radiolytic-hydrogen generation. Subsequent real-time radiography revealed satts packaged in polyethylene bottles. An IDC 411 ER salt drum, D50550, revealed an elevated level of hydrogen, 3.8 volume\%; this result initiated plans to pertorm an "autopsy" on the drum which included detailed headspace gas sampling of the three primary containers, polyethylene bottles, as well as sampling of the bottle contents. The sampting of this drum occurred in the March to April 1995 time-frame.

The observations recorded at these sampling evolutions are summarized below in section 1.1; the anatytical results are summarized in section 1.2 .

\subsection{Observations}

On September 29. 1994, three electroretining salt containers were sampled: containers 5800652 , 5800677 , and 5800629. All three were generated in September or October of 1989. Secondary containment for all three of the salts consisted of a Vollrath 8802 stainless-steel can; all three cans were in excellent condition (Ref. Draft No. 4 Notes to K. A. Phillips from W. A. Averill, October 5, 1994). The primary containers, Vollrath 8801 stainless-steel cans, were tape-sealed and packaged in standard PVC O-ring bags. The primary containers were in excellent condition with no indication of corrosion. The PVC plastic was light brown to dark brown at the bottom of the can and stuck to the bottom of each can. The plastic on container 5800629 was brittle: the plastic on the other two was not brittle and required a knife to tear. The pigtail plastic could not be directly seen since it was covered with yellow tape, however, that tape 
J. Ball

July 22, 1996

KAP-012

Page 2

seemed to be in good condition. The outer bag material was polyethylene and was in good to excellent condition. The salt was moderately to extremely fractured. The largest pieces were approximately $2-4^{*}$ and approximated irregular spheroids and ellipsoids. Half to most of the material was very fine to tine. There were a tew crucible shards found. On the surface of container 5800652 there was a fine purplish colored material which was restricted to that bcality. This purple material appeared lumpy. but disintegrated into a tine powder upon touching. The salts had about 10 to $50 \%$ of "black" or very dark chunks. Most of the fine material was "white" or lighter (yellow-green) in color. The net weights were determined during the evolution and a 0.4 to 0.5 wt.\% gain was observed. Since the ER saht base-salt is not hygroscopic, the increase is most likely attributed to oxidation of plutonium.

The autopsy of drum 050550 occurred in the March to April 1995 time-frame. The drum contained three residue containers, all of which were sampled: 4110328, 4110329, and 4110330. The drum was lined with a rigid polyethylene drum liner and one taped, heavy-gauge flexible drum liner (Ret. Mr to K. A. Phillips from W. A. Averill, WAA-002-96, March 14, 1996). The Radiological Control Technician (RCT) noted that there was removable contamination present inside the liner with counts running 2000-5000 dpm. Primary containment consisted of 2-liter Nalgene ${ }^{\circledR}$. wide-mouth, high-density potyethylene bottles with white plastic, screw-on lids. The bottles were generally dark gray or dark green to yellow-green in color. due to a substantial coating of dust on the inside of the bottles. One of the bottles. 4110330 . had a dusting of powder on the external surface. It is not clear as to whether the powder leaked out of the bottle via lid threads or whether the container was contaminated prior to being bagged out. There were a few to several dark brown to black spots on the bottles scattered over the surface. These spots varied in diameter from about 1/4-1". The primary containers were packaged in standard PVC O-ring bags (yellow to light brown in color with several darker brown spols scattered over the surface). The outer bag material was light-gauge polyethylene: the outer polyethylene bags were in excellemt condition. The salt consisted of large, dark gray or dark green to green-yellow chunks which were about $2-4^{*}$. blocky in shape and roughly isotropic. The chunks made up roughly 50 to $75 \%$ of the satt material in the bottle. Approximately 15 to $20 \%$ of the material was small $\left(1 / 2-3 / 4^{7}\right)$ chunks of dark gray or dark green to greenyellow salt. The small chunks were more friable than the large chunks. The remainder of the material was an extremely line dark gray or dark green to green-yellow powder. This powder was readily made airborne when the mass of material was disturbed. The salt from each polyethylene boltie was repackaged into three Vollratt 8801 cans. The cans were placed in the original drum.

\subsection{Summary of Analytical Results}

When the six IDC 411 containers were sampled, only three samples were taken for analysis: the samples were submitted for water reactivity testing, impact testing, and $x$-ray diffraction (XRD). None of the.six containers sampled exceeded the Department of Transportation (DOT) limit for dangerous-when-wet materials ( 1 liter $/ \mathrm{kg} / \mathrm{hr}$ ). Impact lest results were negative: the salts sampled showed no evidence of being shock-sensitive. The major constituents found with $x$-ray ditfraction were $\mathrm{KCl}, \mathrm{NaCl}$, and

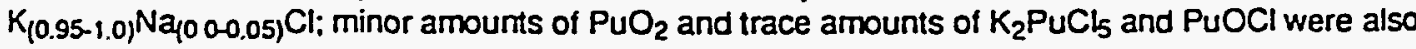
identified.

The detailed headspace gas sampling of the three polyethylene bottles; and the respective bag-out bags in the high hydrogen drum showed a concentration gradient of hydrogen from the boltle to the bag. There was a significant delay between when the drum was headspace gas sampled and when the detailed bag and boltle samples were taken. The conclusion reached from the sampling is that the dnum fitter does an adequate job of venting any radiolytic hydrogen generated. and the polyethylene bottles and bag-out materials are not hermetic. The detailed results will be covered in the headspace gas sampling repon.

\subsection{CONTAINERS SAMPLED}

Fifty-eight residue containers have been sampled so far this fiscal year and are listed in Appendix 1. Appendix 1 is sorted by IDC and represents a top-level summary of the characterization effort. The 
J. Ball

July 22, 1996

KAP-012

Page 3

Appendix 1 matrix gives the pass/fail determination for a number of characteristics. If the characteristic was not assessed for a particular container, N/A is shown. The amount of dispersible fines in the container represents an approximate value which is based on the particle size distribution of the fines fraction and the relative percentage of fines in the container. If no dusting was observed during sampling and/or there was no fines fraction, a particle size distribution sample was not taken and is recorded as NA. To date, a pass/tail criterion for container radiological surveys has not been completely established. specitically for surveys taken at a meters distance from the comtainer. The WIPPNAC uses $200 \mathrm{mRern} / \mathrm{mour}$ as a fimit for contact or surface dose rate, and this criterion has been incorporated for surface readings. The pass/fail criteria for the other characteristics listed are given below in Table 1.

Table 1. Criteria For Anabytical "Hits" or "Fail"-ures

Characteristic

Pyrophoricity

Water Reactivity

Shock Sensitivity

Oxidizer/Fuel Mixtures

Free Liquids/Moisture

RCRA Ignitability

RCRA Corrosivity

RCRA "D"

RCRA "F"

\section{Criterion for "Hit" or "Fail"-ure}

Significant rate of temperature increase (dT/dt) and/or ignition $<60^{\circ} \mathrm{C}$

Rate of $\mathrm{H}_{2}$ generation exceeding 1 liter/kg material/hour

AudibleNisible sign of reaction (i.e., pop/smoke) at approximately $40 \mathrm{~kg}$ $\mathrm{cm}$ (typical of primers and initiators)

Detection of oxidizer and presence of fuel

Presence through visual examination $0 \mathrm{~B}$ liquid collected after 5 minutes in paint fitter

Liquid with a flash point less than $60^{\circ} \mathrm{C}$ OB non-liquid capable. under standard temperature and pressure, of causing tire through friction. absorption of moisture or spontaneous chemical changes and, when ignited. burns so vigorousty and persistently that it creates a hazard $\mathrm{QB}$ oxidizer as defined in $49 \mathrm{CFR} \$ 173.151$

Aqueous with a $\mathrm{pH} \leq 2$ or $\mathrm{pH} \geq 12 \mathrm{OB}$ liquid which corrodes steel at a rate $>6.35 \mathrm{~mm} / \mathrm{yr}$

Presence of constituents listed in Table 1 of 40 CFR \$261.24, at a concentration equal to or greater than the respective value given in that table

Process knowledge (constituents listed in 40 CFR §261.31)

The heading 'Visual of Primary Container' in Appendix 1 takes into account three primary characteristics: excessive corrosion, pressurization, and loss of containment. If one or more of the characteristics are present then the container fails the visual inspection. All "hits" or "fail"-ures in Appendix 1 are footnoted and the results are given. The dose rates, when taken, are also included in the footnotes.

Currently, the analyses are complete on sixteen containers but the visual reports for eight of the sixteen have not been completed. Pending completion of the visual reports, those eight containers will be summarized in the next monthly status report. Eight containers have been completely characterized and those containers are shaded on Appendix 1. The detailed characterization summaries of those containers 
comprise section 3.0.

\subsection{DETAILED CHARACTERIZATION SUMMARIES}

\subsection{IDC 411 . Electrorefining Salt}

\subsubsection{Observations}

The first three ER salt drums sampled in Building 707 this fiscal year had a șimilar packaging configuration to drum D50550. The drums sampled were D50560 - package 4110311 (Ref. Itr to K. A. Phillips from W. A. Averill, WAA-003-96, March 14, 1996), D50117 - package 4110225 (Ref. Itr to K. A. Phillips from W. A. Averill, WAA-96-022. March 7, 1996) and D49516 - package 4110306 (Ref. Hr to K. A. Phillips from W. A. Averill, WAA-96-023, March 8, 1996). The number of items per drum varied from six to fourteen.

The primary containers were 2-liter Nalgene wide-mouth, high-density polyethylene bottles with white. plastic, screw-on lids. The bottles were in good to excellent shape: some appeared to be coated with a dark-green dust on the inside and others showed no discoloration. The PVC bags were light to medium brown in color with several dark brown spots scattered over the surface. The outer polyethylene bags which were in excellent condition. showed no sign of deterioration but slight discoloration (uniform light brown to green in color). Also; the tape was slightly discolored, tuming brown.

The salt in 050560 consisted of large (>67), dark, purplish-colored chunks, blocky in shape and roughly isotropic: the chunks made up roughly $50 \%$ of the salt material in the bottle. Approximately $10 \%$ of the material was small (1/8-3/47) chunks of dark gray satt. The small chunks were very easily broken into smaller chunks. The remainder of the material was an extremely fine dark green, easily dispersible, powder. The satt in D50117 was generally light gray with about $10 \%$ of the material consisting of medium to large cream-colored chunks. The fine particle size fraction made up about $30 \%$ of the material. About $5 \%$ of the material consisted of chunks $1 / 4-1^{\prime \prime}$. The remainder was material greater than $2^{*}$. The satt in D49516 consisted of dark gray to black chunks. Approximately $60 \%$ were $1-4^{\circ}, 20 \% 1 / 8-1^{\circ}$, and $20 \%$ less than $1 / 8^{*}$. It was estimated that approximately $5 \%$ of the material was dispersible (less than $10 \mu \mathrm{m}$ ).

After taking package 4110225 out of the drum D50117, the package was placed into a polyethylene bag. taped closed, and surveyed for radiation. The package emitted $38 \mathrm{mRem} / \mathrm{hr}$ at $30 \mathrm{~cm}$ from the surface of the package. Similarly, after taking package 4110306 out of the drum D49516, the package was placed into a polyethylene bag, taped closed, and surveyed for radiation. The package emitted $167 \mathrm{mRem} / \mathrm{hr}$ gamma and $1.1 \mathrm{mREM} / \mathrm{hr}$ neutron at the surface of the package. Salt from each of the six polyethylene bottles in 050560 was repackaged into three Vollrath 8801 cans for a total of eighteen cans. All of the cans and bottles were placed in the original dnums.

\subsubsection{Summary of Analytical Results}

Six samples were taken from each of the IDC 411 containers; differential themal analysis (DTA), impact lest, total metals, water reactivity, XRD, and particle size distribution of the fines fraction. The DTA and impact test revealed no indication of pyrophoricity or shock sensitivity, respectively. One of the three comtainers failed total metals for $\mathrm{Pb}$, but TCLP was subsequently run and the material passed; the salts are nonhazardous for RCRA metals. The $1 \mathrm{lkg}$ salt/hr DOT water reactivity limit was not exceeded. XRD confirmed the salt matrix of the electrorefining salts (IDC 411); major constituents, $\mathrm{NaCl}$ and

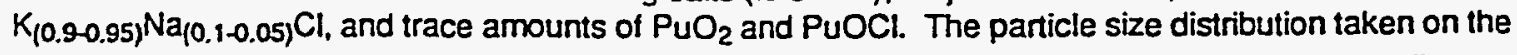
fines fraction of the samples revealed that there is less than 0.2 weight percent (wt\%) dispersible fines $(10 \mu \mathrm{m})$. The weight percent is estimated to be considerably less for the whole container, approximately 0.04-0.08 wt\%. 
J. Ball

July 22, 1996

KAP-012

Page 5

\subsection{IDC 407 . Molten Salt. $8 \%$ Pulverized}

\subsubsection{Observations}

Five IDC 407 molten salt extraction (MSE) salt containers have been sampled and analyzed. Two of the five were mislabeled and the primary containers identified them as IDC 416, Zinc-Magnesium Alloy Metal. The three IDC 407 containers sampled were 5200722 (Ret. Itr to K. A. Phillips from A. M. Murray, AMM001-96. January 9, 1996). 5200720 (Ret. Hr to K. A. Phillips from A. M. Murray. AMM-001-96, January 9. 1996), and 5200721 (Ref. Itr to K: A. Phillips from A. M. Murray, AMM-005-96. January 15, 1996). The packaging configuration was the same on all three salts. The primary container was a tir-plated, mild-steel. produce can. The external surface of the produce cans had streaks of black tar where the inner plastic bag had been stuck. Around the black tar areas there was sometimes a halo of nust about 1/8" wide. The inner surface of the cans was pristine. The inner plastic bags did show signs of degradation. The bags were discolored (yellow) but still pliable. Wherever the inner bag touched the inner can, there was signiticant degradation of the plastic, i.e., the plastic was black and tacky. As the inner plastic bag was removed, the blackened areas stuck to the inner container and left a black residue on the inner container. The degraded areas of the inner bag seemed to tear easily. The outer plastic bags were in good shape. There were no signs of deterioration. The outer, secondary containers were Vollrath 8802 stainless-steel cans. Both the external and internal surfaces of the cans were in good shape. No signs of corrosion were observed. The tape on the outside of the can was in good shape. The satt was light gun metal gray and ranged from a tine powder to chunks 1-4" (the relative percentages were not assessed). In container 5200720 there was a thin piece of metal which was probably from the satt/metal button interface.

The IDC 416 packaging configuration was similar to the IDC 407: produce can in a Vollrath 8802 . stainless-steel can. The containers sampled were $07037 \mathrm{~B}$ and 07031E (Rel. It to K. A. Phillips from A. M. Murray, AMM-001-96. January 9, 1996). The internal surtaces of the produce cans were pristine. On the external surface of container 07031E. spectically the bottom of the can, mild corrosion was observed (no other details were given); the external surface of 07037B showed no signs of corrosion. The tape on the outside of the cans was in good shape. The inner plastic bags were slightly discolored (pale to golden yellow). There were no signs of degradation and the material was still pliable. The outer plastic bags were in good shape with no signs of deterioration. The material was dark gray and ranged from powder to slivers 10 large chunks. The large chunks had spherical suriaces indicative that the material had settled to the bottom of the processing crucible. Many small metallic chips were present in the powder and the chunks glinted as they were rotated in the light. Metal probably makes up a substantial portion of the chunks' composition.

\subsubsection{Summary of Analytical Results}

Five samples were taken from each of the IDC 407 containers: DTA, total metals, water reactivity, XRD, and particle size distribution of the fines fraction. The DTA revealed no indication of pyrophoricity. Two of the three containers failed total metals for $\mathrm{Cr}$ and $\mathrm{Pb}$. but TCLP was subsequently nu and the two that failed totals passed TCLP: the salts are nonhazardous for RCRA metals. The $1 \mathrm{Vkg}$ salt/hr DOT water reactivity limit was not exceeded. XRD identified $\mathrm{CaCl}_{2}$ as a major constituent in the IDC 407 samples, a sath not expected in this MSE IDC. Another major constituent, $\mathrm{KCaCl}_{3}$, was idemitied as well as trace-to-minor amounts of $\mathrm{PuO}_{2}$, and trace quantities of $\mathrm{NaCl}, \mathrm{KCl}$, and $\mathrm{MgO}$. The particle size distribution taken on the lines fraction of the samples revealed that there is less than 0.4 weight percent dispersible tines $(10 \mu \mathrm{m})$. The weight percent is considerably less for the whole container.

Two of the containers sampled (07037B and 07031E) were identified in the SAN data base as IDC 407 MSE satts, but the primary containers were labeled as IDC 416 . IDC 416 residues were generated as part of the pyroredox process development eftort in the late 1970 s at Rocky Flats (Ret. Hr to K. A. Phillips from A M. Murray, AMM-019-96. April 16, 1996). There were three types of IDC 416 residues generated as

\footnotetext{
Sato Sites of Colorado. Rocky Flats Environmental Technology Site. P. O. Box 464. Golden. Co 80402-0464
} 
J. Ball

July 22, 1996

KAP-012

Page 6

part of the development: a $\mathrm{Zn}-\mathrm{Mg}$ alloy, a Ca-Mg-Zn alloy and a Ca-Zn alloy. Six samples were taken from each of the IOC 416 containers; total metals, total semi-volatile organic analytes (SVOAs), total volatile organic analytes (VOAs), water reactivity, XRD, and particle size distribution. When exposed to water, the material sampled generated hydrogen in excess of the DOT limit ( 1 liter/kg sample/hour) consistently for the seven-hour duration. Both samples failed total metals for $\mathrm{Cd}, \mathrm{Cr}$, and $\mathrm{Pb}$. Additionally, container 07031E lailed for Se. Both materials were submitted for TCLP and passed: the alloy material is nonhazardous for RCRA metals. X-ray diffraction identified $\mathrm{Zn}$ and $M g \mathrm{Zn}_{2}$ as major constituents: $\mathrm{NaCl}$ and $\mathrm{Zn}$, minor constituents: $\mathrm{Mg}$, probable minor-to-irace; and $\mathrm{KCl}, \mathrm{MgO}, \mathrm{NaCl}$, and $\mathrm{Mg}_{2} \mathrm{Zn}_{11}$ as probable trace quantities. The particle size distribution taken on the fines fraction of the samples revealed that there is less than 0.9 weight percent dispersible fines $(10 \mu \mathrm{m})$. The weight percent is considerably less for the whole container.

Samples for volatile organic and semi-volatile organic analyses (VOA and SVOA) were taken for the two IDC 416 containers. One SVOA "hit" was observed for one of the two samples: the "hit" was Di-nbutylphthalate, an analyte apparently given off from leaded rubber gloves. Several VOA "hits" were observed with both samples analyzed. The components that were "hits" are listed in Table 2 with the respective concentrations. The samples were stored in plastic sampling vials: this practice has since been abandoned and glass vials are used exclusively for VOA and SVOA samples. Since the alloy matenal was generated from a pyrochemical process, it is proposed that the by-product from the degradation of the plastic packaging material and/or contamination from the glovebox might be adsorbing onto the residue. Currently this has not been contirmed.

Table 2. VOA "Hits" for IDC 416 Residue Containers

Concentration (ppb)

$\begin{array}{lcc} & \text { Container } 07037 \mathrm{~B} & \text { Container 07031E } \\ \text { Chloroethane } & 760 & 250 \\ \text { Acetone } & 6400 & 2200 \\ \text { Methylene Chloride } & 660 & 240 \\ \text { 2-Butanone } & 1400 & 630 \\ \text { Chlorotorm } & 500 & 68 \\ \text { Benzene } & 350 & 210 \\ \text { Carbon Tetrachloride } & 240 & - \\ \text { 1,2-Dichloroethane } & 83 & - \\ \text { Trichloroethene } & 76 & - \\ \text { Toluene } & 46 & -- \\ \text { Tetrachloroethene } & 120 & --\end{array}$


J. Ball

July 22, 1996

KAP-012

Page 7

cc:

Averill, B.

Bokan, S.

Brugh, $M$.

Burns, $T$.

Catlett, D.

Conner, $B$.

Danio, L.

Dustin, L.

Edrich, $P$.

Ferrera, K.

Glenn, T.

Gregory-Frost, L.

Hammetter, J.

Horton, J.

Hunter, D.

Moynihan, C.

Moody, D.

Muscatello, T.

Newlan, J.

Ozeary, G.

RESIDUE STABILIZATION PERSONNEL Ayan, $K$.

Tumer, C.

Wierzbicki, B. 


\section{APPENDIX B}

\section{EFFECTS OF CHLORIDE IONS ON CEMENT}

\section{B.1 EFFECTS OF CHLORIDE IONS ON THE SETTING PROPERTIES OF CEMENT}

Typically, only a small amount of the chloride in the chloride-containing waste would be chemically fixed in the hydrates of the cement (this is the case with many waste species). The remainder of the chloride would exist as crystals embedded in the hydrate network. The porosity of the waste form would be the factor determining the leach rate. A low porosity, high-tortuosity matrix would help aid the retention of this ion. Many studies performed on chloride diffusion favor the hypothesis that the finer the microstructure, the smaller the diffusion of the chloride ion. ${ }^{1}$

Chloride anions can alter the amount of time it takes for the cement to set. The effect of chloride on the cement setting time depends upon the nature of the cation and the concentration of the salt. $\mathrm{Lea}^{2}$ presents the following data on the influence of chloride:

- Calcium chloride: this salt has a dual effect upon the set because at concentrations $<1$ wt \% (based on the weight of the cement), the action of calcium chloride is to increase the setting time, while the addition of larger amounts decrease the setting time. In some cases, the addition of $3 \mathrm{wt} \%$ calcium chloride can cause a very short setting time (a flash set).

- Sodium chloride: This salt produces erratic effects. It decreases the setting time of some Portland cements and increases that of others.

- Aluminum and magnesium chloride: These salts substantially reduce the setting time of the cement.

- Alkali chlorides: The effect of alkali chlorides upon the hydration of cement is reported to be variable and otherwise minimal.

- Barium and strontium chloride: These salts reduce slightly the setting time of the cement.

- Ammonium, iron, and cobalt chloride: The setting time is increased if the concentration of the ammonium, iron, and cobalt chlorides in the mortar is below 2 wt \% (based upon the weight of the cement). Conversely, a concentration of these salts exceeding 2 wt \% decreases the settiing time.

No work has been done to optimize a cement-based matrix to stabilize pyrochemical salts from plutonium operations. Possibly, the mass of radioactive materials ( ${ }^{239} \mathrm{Pu}$ mass equivalents), not the salt content, would determine the salt-waste loading. Studies have reported successful waste forms or cement-based matrices containing chloride loadings $>10 \mathrm{wt} \%$. Two such studies are presented in Sects. B.2 and B.3.

\section{B.2 STABILIZATION OF INTEGRAL FAST REACTOR SALT WASTES}

Chloride-rich waste solutions were generated at Argonne National Laboratory (ANL) as a byproduct of the Integral Fast Reactor (IFR) fuel cycle. Starting in 1988, ANL worked to develop a cement-based matrix (grout) to immobilize IFR salt wastes. ${ }^{3}$ After treatment, the grout was placed in corrosion-resistant containers and sealed. The grout had to be sufficiently 
fluid to be pumped into containers where it solidified into a stable, leach-resistant material. The setting time had to be longer than a few hours in order to allow sufficient processing time. The product reached a compressive strength of about $7 \mathrm{MPa}$ within three days to permit handling.

Fission products in the IFR salt wastes generated heat of about $0.6 \mathrm{~W} / \mathrm{kg}$ for a mortar containing $10 \mathrm{wt} \%$ waste salt. Therefore, the effects of temperatures up to $150^{\circ} \mathrm{C}$ had to be considered. Waste loading was limited to $10 \mathrm{wt} \%$ because of heat generated by the radioactive components of the waste, not the interactions of the salt.

Two salt mixtures were used in the ANL study: (1) calcium chloride, $33 \mathrm{wt} \%$, and sodium chloride, $67 \mathrm{wt} \%$, and (2) potassium chloride, $44 \mathrm{wt} \%$, and lithium chloride, 56 wt \%. Cement mixes with several fly ashes, sands, and clays were evaluated with respect to fluidity, setting times, and compressive strength. In the absence of a leaching standard for chloride ions, chloride leaching rates were evaluated using the ANS 16.1 leaching procedure. ${ }^{4}$

Tests at ANL indicated that the IFR requirements were met with a mix of about 45 wt \% Type I Portland cement, 27 wt \% class F fly ash, and 28 wt \% water; this mix contained up to $10 \mathrm{wt} \%$ salt. The weight percent of the fly ash was reduced by the weight percent of the introduced salt waste. The limiting factor was the heat produced by the contained fission products. This mix design resulted in a mortar which could be pumped; it had an initial set time of $>2 \mathrm{hr}$. The mortar developed a compressive strength of 10 to $20 \mathrm{MPa}$ after $3 \mathrm{~d}$ curing at room temperature and 50 to $70 \mathrm{MPa}$ after $56 \mathrm{~d}$. The leach indices for chloride were in the range of 7 to 8 (the higher the leach index, the more leach resistant the waste form). Investigations were conducted with salt (calcium chloride, $33 \mathrm{wt} \%$, and sodium chloride, $67 \mathrm{wt} \%$ ) loading up to $18 \mathrm{wt} \%$. Initial setting times were about $1.6 \mathrm{hr}$, with compressive strengths up to $14.6 \mathrm{MPa}$ after curing for $56 \mathrm{~d}$. No chloride leach data were collected on this waste loading. One conclusion reached in the ANL study was that up to $18 \mathrm{wt} \%$ salt in the mortar waste form was possible, but the long-term integrity of the waste form could be jeopardized by using more than 18 wt \% salt.

There was no attempt made to optimize the waste loading of the chloride salt as thermal properties of the waste solution were the limiting factors. Depending upon performance criteria (e.g., U.S. Department of Energy (DOE) Waste Isolation Pilot Plant waste acceptance criteria or U.S. Nuclear Regulatory Commission and DOE orders) a mix could be designed to exceed the $18 \mathrm{wt} \%$ salt loading reported in the ANL study.

\section{B.3 SALT-CEMENT MIXES FOR SEALING BOREHOLES}

Salt (typically sodium chloride)-cement mixtures or saltcretes have been widely used in the oil-well cement industry to ensure good bonding between the grouts and the sections of shale encountered in the wall of the hole. ${ }^{5}$ The addition of salt to a cement slurry used in an oil-well penetrating a salt formation is necessary to prevent solubilization of the latter.

During the mid 1970s, work was performed at Oak Ridge National Laboratory (ORNL) to support efforts by the DOE Office of Waste Isolation to develop sealing materials for boreholes and mine shafts in potential waste disposal repository sites. ${ }^{6} \mathrm{~A}$ wide variety of cements and fly ashes were investigated in the ORNL effort. The parameters of principal interest were salt loading, setting time, and compressive strength.

Mixes with salt contents of 10,30 , and $63.2 \mathrm{wt} \%$ salt were tested. The mixture consisted of $23 \mathrm{wt} \%$ Portland cement and $13.8 \mathrm{wt} \%$ water $(\mathrm{W} / \mathrm{C}=0.60)$. To permit a range of salt contents, the sand composition was varied from 0.0 to $63.2 \mathrm{wt} \%$. The constituents of the $63.2 \mathrm{wt} \%$ salt mixture were $23.0 \mathrm{wt} \%$ Type I Portland cement, $63.2 \mathrm{wt} \%$ salt, and $13.8 \mathrm{wt}$ $\%$ water. The initial setting time for the $63.2 \mathrm{wt} \%$ salt was $10.9 \mathrm{hr}$ and the final set was 
achieved in $14.5 \mathrm{hr}$. The compressive strength reached 19.0 $\mathrm{MPa}$ after the mortar cured for $91 \mathrm{~d}$. Salt loadings of $30 \mathrm{wt} \%$ had initial setting times of $12.5 \mathrm{~h}$ and the final set was reached in $16.8 \mathrm{hr}$; a compressive strength of $26.2 \mathrm{MPa}$ was measured after a $91-\mathrm{d}$ curing period. The cement had to be mixed with a saturated salt solution to be effective.

Additional work was done with a variety of fly ashes. It was established that salt contents of up to $30 \mathrm{wt} \%$ could be achieved in a mix containing Portland cement, water, salt, and fly ash.

\section{B.4 REFERENCES}

1. Glasser, F. P., "Progress in the Immobilization of Radioactive Wastes in Cement" in Cement and Concrete Research, 22:201-16 (1992).

2. Lea, F. M. The Chemistry of Cement and Concrete, Chemical Publishing Company, New York, 1971.

3. Fischer, D. F. and Johnson, T. R., "Immobilization of IFR Salt Wastes in Mortar," Proceedings of The International Topical Meeting on Nuclear and Hazardous Waste Management Spectrum 88, Sept.11-15, 1988, Pasco, Wash.

4. Measurement of the Leachability of Solidified Low-Level Radioactive Wastes, Draft, American Nuclear Society Standards Committee, Working Group ANS 16.1 Washington, D.C., Feb. 1986.

5. Smith, D. K., Cementing, Society of Petroleum Engineers of AIME, 1976.

6. Moore, J. G., Morgan, M. T., McDaniel, E. W., Cement Technology for Plugging Boreholes in Radioactive Waste Repository Sites: Progress Report for the Period October 1, 1977 to September 30, 1978, ORNL-5524, Oak Ridge National Laboratory, Oak Ridge, Tenn., 1979. 
ORNL DWG 83-194R

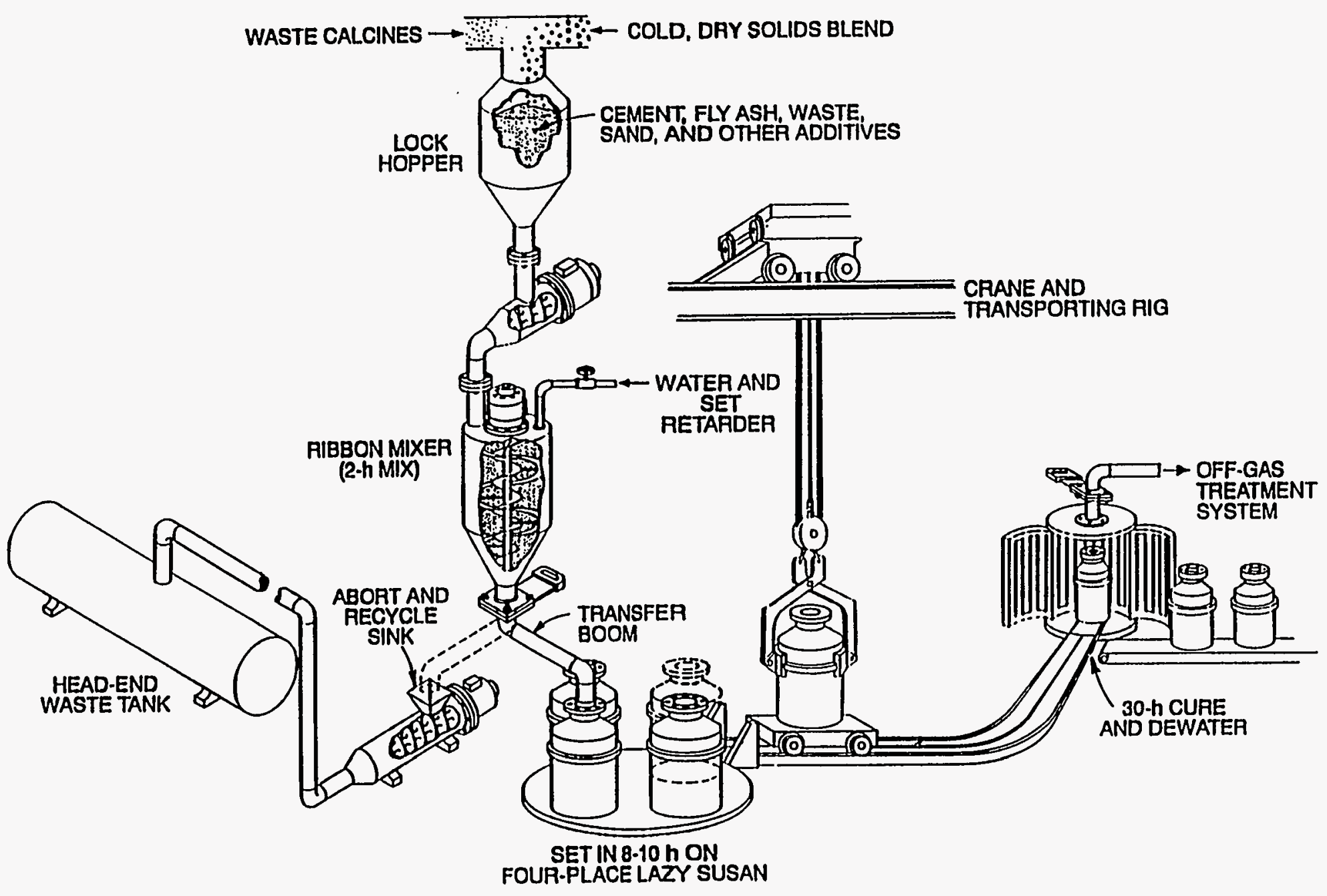

四最

总 


\section{APPENDIX D}

\section{BOROSILICATE GLASS}

Vitrification techniques, equipment, processes, and remote operations for solidifying high-level waste (HLW) in borosilicate glass have been developed and studied for over 35 years. This technology has reached a high degree of technical maturity. Industrial demonstration of the vitrification process has been occurring since 1978 . Only recently have scientists, engineers, and administrators advocated vitrification for wastes other than HLW. The process was considered expensive and "over-kill" for low-level and mixed waste.

The U.S. Department of Energy (DOE) officially chose borosilicate glass as the final waste form for HLW in 1981 after an extensive evaluation program. ' Nine countries are engaged in some form of borosilicate waste form development.

In 1993, DOE decided to consider vitrification for wastes other than HLW. This decision stimulated interest in a number of vitreous matrices that were developed and abandoned when the decision was made in favor of borosilicate glass for HLW.

Information regarding the properties and characterization of HLW vitrified in borosilicate glass is readily available. The waste form usually contains less than $30 \mathrm{wt} \%$ of waste solids; however, the vitrification process generally reduces the waste volume significantly. Specific waste streams can be added at higher temperature levels and, under conditions where waste contains sufficient glass-forming materials, a glass containing only waste can be produced.

Vitrification can be accomplished by a wide variety of processes. These include fossil fuel combustion, Joule (electric) heating, plasma arc melting, graphite arc melting, in situ vitrification, and induction and microwave heating. The choice of a melter will depend upon the characteristics and requirements of a specific waste stream.

Because of the high temperatures $\left(1200-1600^{\circ} \mathrm{C}\right)$ required, borosilicate glass would not be suitable for immobilizing pyrochemical salts. The chloride anions, as well as calcium cations, become mobile and vaporize at substantially lower temperatures. To illustrate a borosilicate glass waste preparation facility, a flow sheet of the Savannah River Site Defense Waste Processing Facility and a melter schematic are given in Appendix F.

\section{REFERENCES}

1. U.S. Department of Energy, The Evaluation And Selection Of Candidate High-Level Waste Forms, DOE/TIC 11611, Mar. 1982. 


\section{Battelle, Pacific Northwest Laboratory}

Waste to Glass

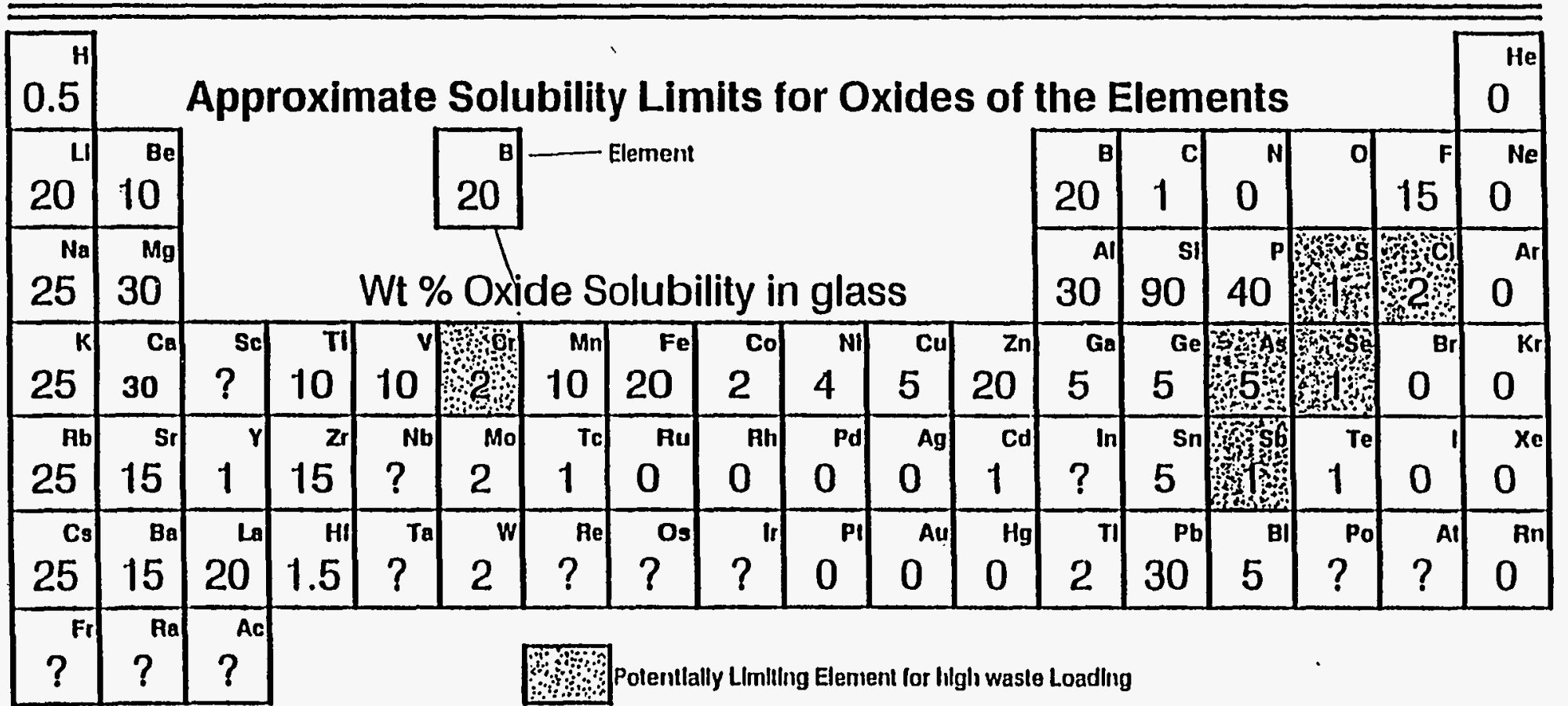

\begin{tabular}{|c|c|c|c|c|c|c|c|c|c|c|c|c|c|}
\hline $5^{\mathrm{Ce}}$ & $10^{\mathrm{Pr}}$ & $20^{N d}$ & $5^{\mathrm{Pm}}$ & $\begin{array}{c}\mathbf{s m} \\
1+\end{array}$ & $\begin{array}{c}\text { Eu } \\
1+\end{array}$ & $6^{\text {Gd }}$ & $?^{\mathrm{Tb}}$ & $\begin{array}{c}\text { Dy } \\
2+\end{array}$ & $?^{\mathrm{HO}^{\mathrm{O}}}$ & $?^{\text {Er }}$ & $?^{\mathrm{Tm}}$ & $?^{Y b}$ & $?^{\mathrm{Lu}}$ \\
\hline $6^{T h}$ & $?^{\mathrm{Pa}}$ & $20^{u}$ & & & $2^{A m}$ & $1^{\mathrm{Cm}}$ & & & & & & & \\
\hline
\end{tabular}




\section{APPENDIX F \\ PRIMARY DEFENSE WASTE PROCESSING FACILITY MELTER OFF-GAS SYSTEM AND MELTER DRAWING}

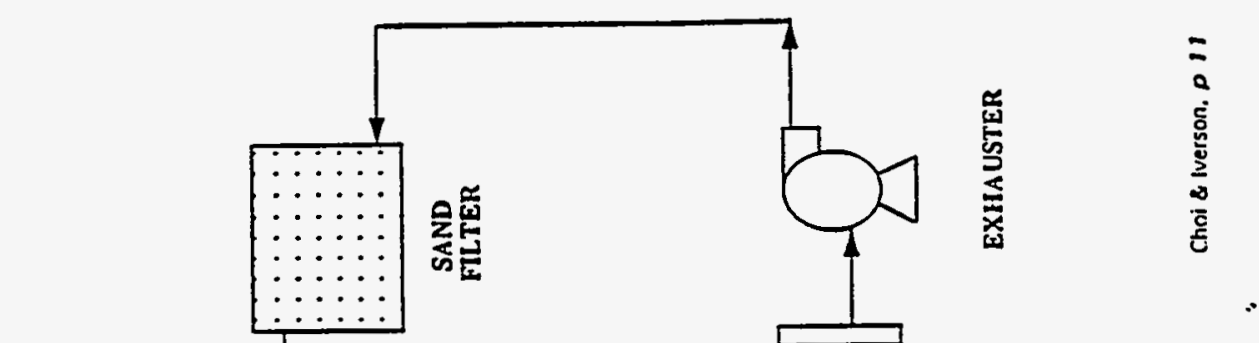

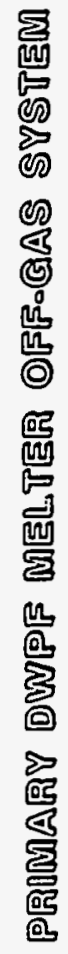
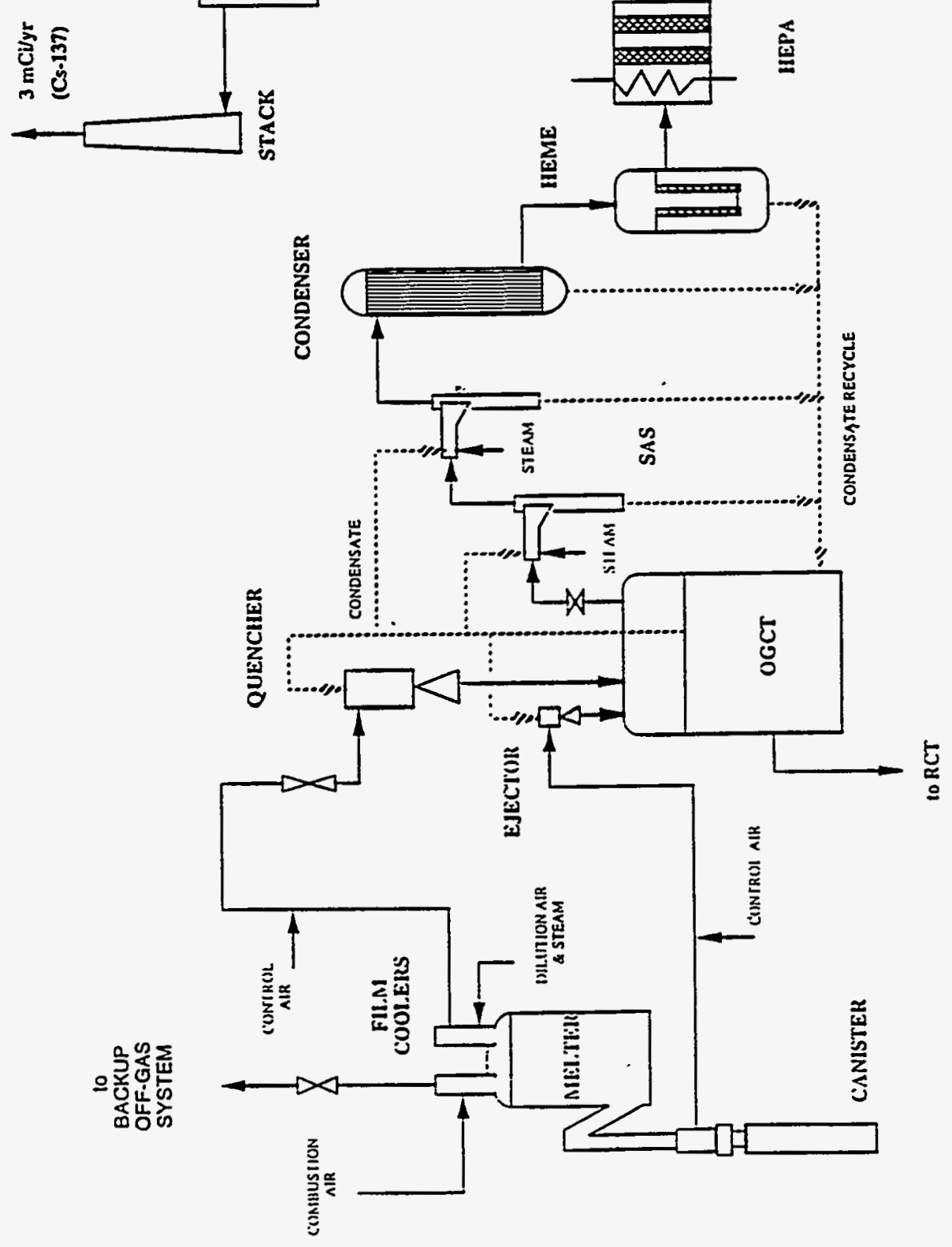


\section{Developing superior glass}

Proficiency in blending the best glass

"We have cradle to grave expertise in how to take waste and develop the best glass...a

Vierification of $H L W$ ot SRS. development," says Carol Jantzen, of the glass technology group. The process models she developed ensure that the meit's viscosity or pourability is right for processing, and that the glass
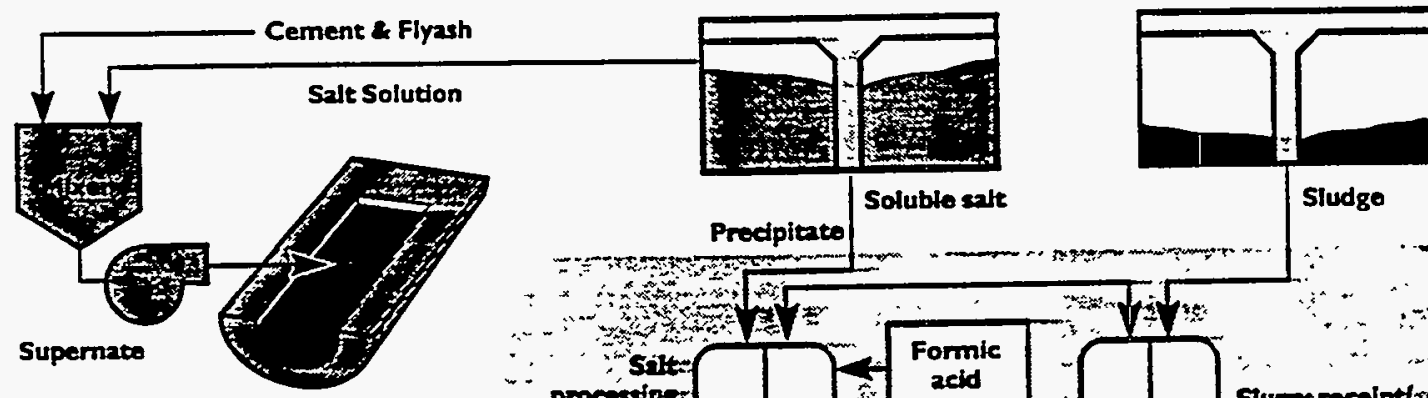

Sludge

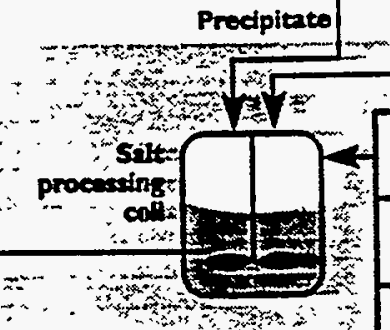

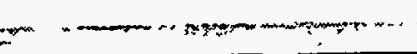
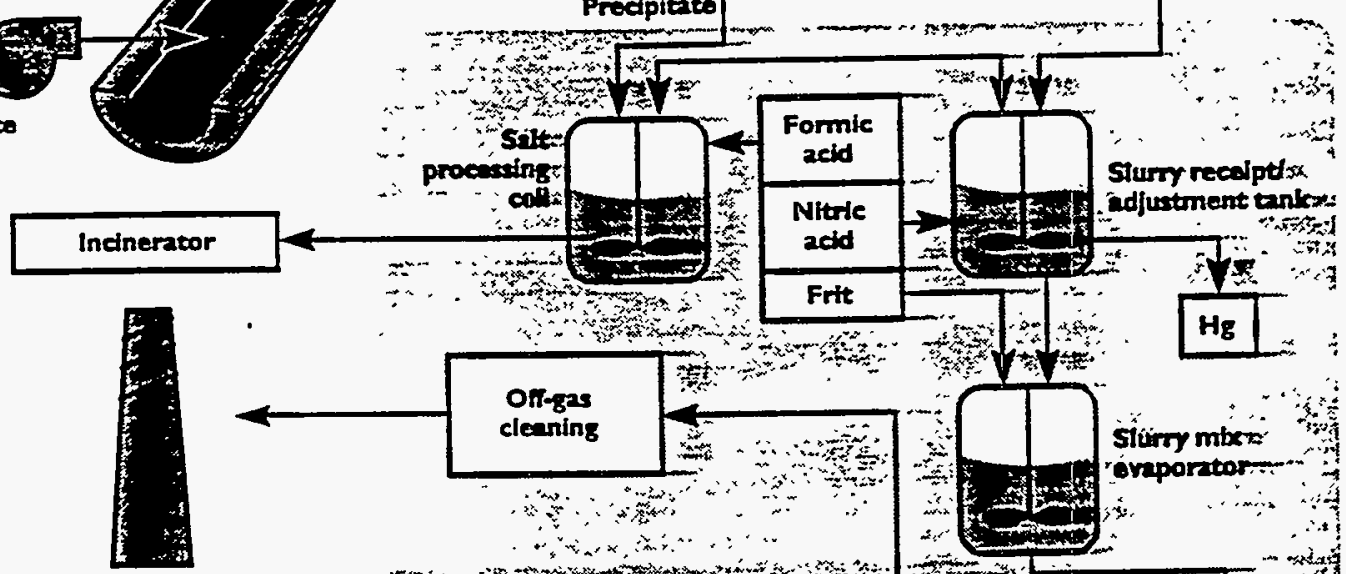

SAurry recolptisx

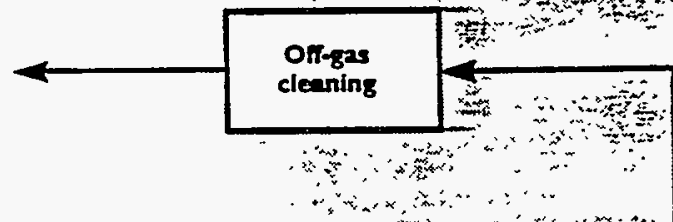

$x$,

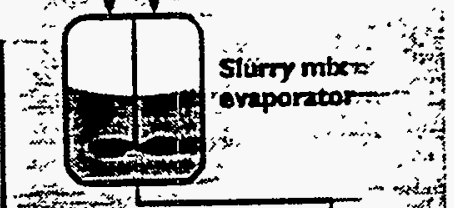

Interim storage for eventual shipment to a federal repository

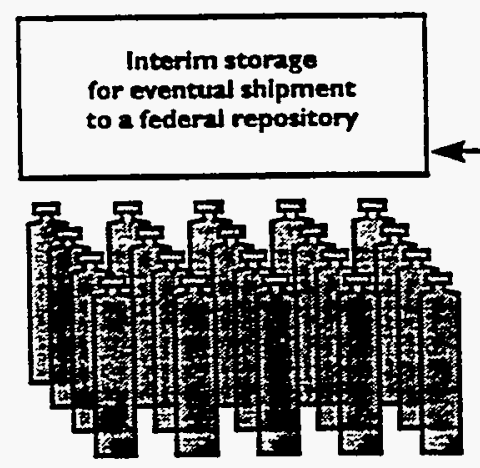

作

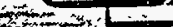
$-\infty$
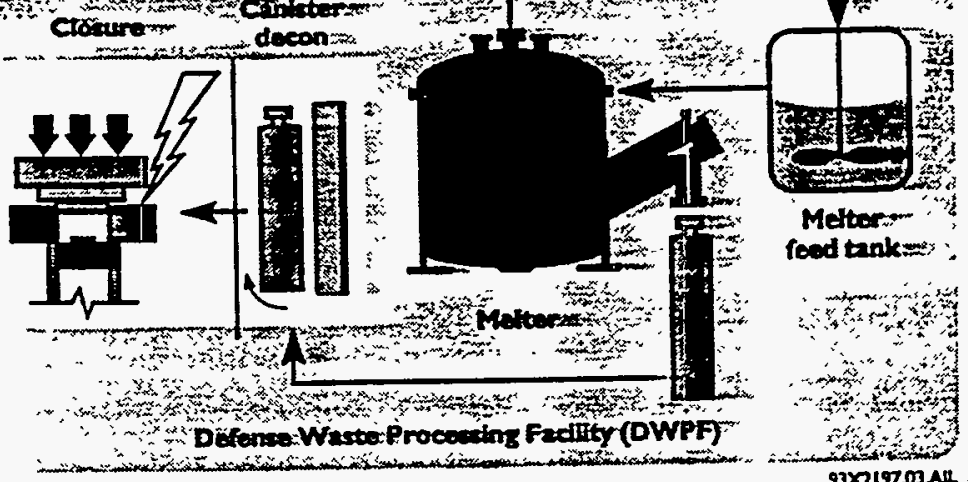
waste is durable. Using Carol's models on a personal computer. durability and other important properties can be estimated from the melter feed ingredients. For more complex problems, the product composition control system (PCCS), built upon SRTC's proprietary statistical process control algorithm, allows for random variations in the vitrification process. The result is reliable production of a durable glass produce.

There are several types of waste streams suitable for vitrification, including.

- Sludges or filter ake, composed of metal hydroxides. carbonates, nitrates or silicates

- Ion exchange resins (inorganic and organic), inorganic filter media, zeolites

- Asbestos or glass fiber-filters

- Incinerator ashiand: offigas liquor."

- Soills or geologic materials -

- Cönereto.

- Radioactively contaminated materials

\section{A generation of melter experience}

SRTC's long history of melter technology has resulted in an experienced, expert steff. The variety of melters, equipped with either dry off-gas systems (to remove particulate matcer from non-acidic wastes with no

Deforse Woste frocessing Focity (DWPF) metter

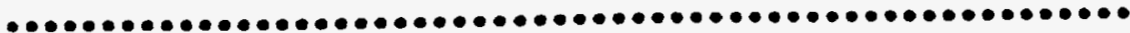

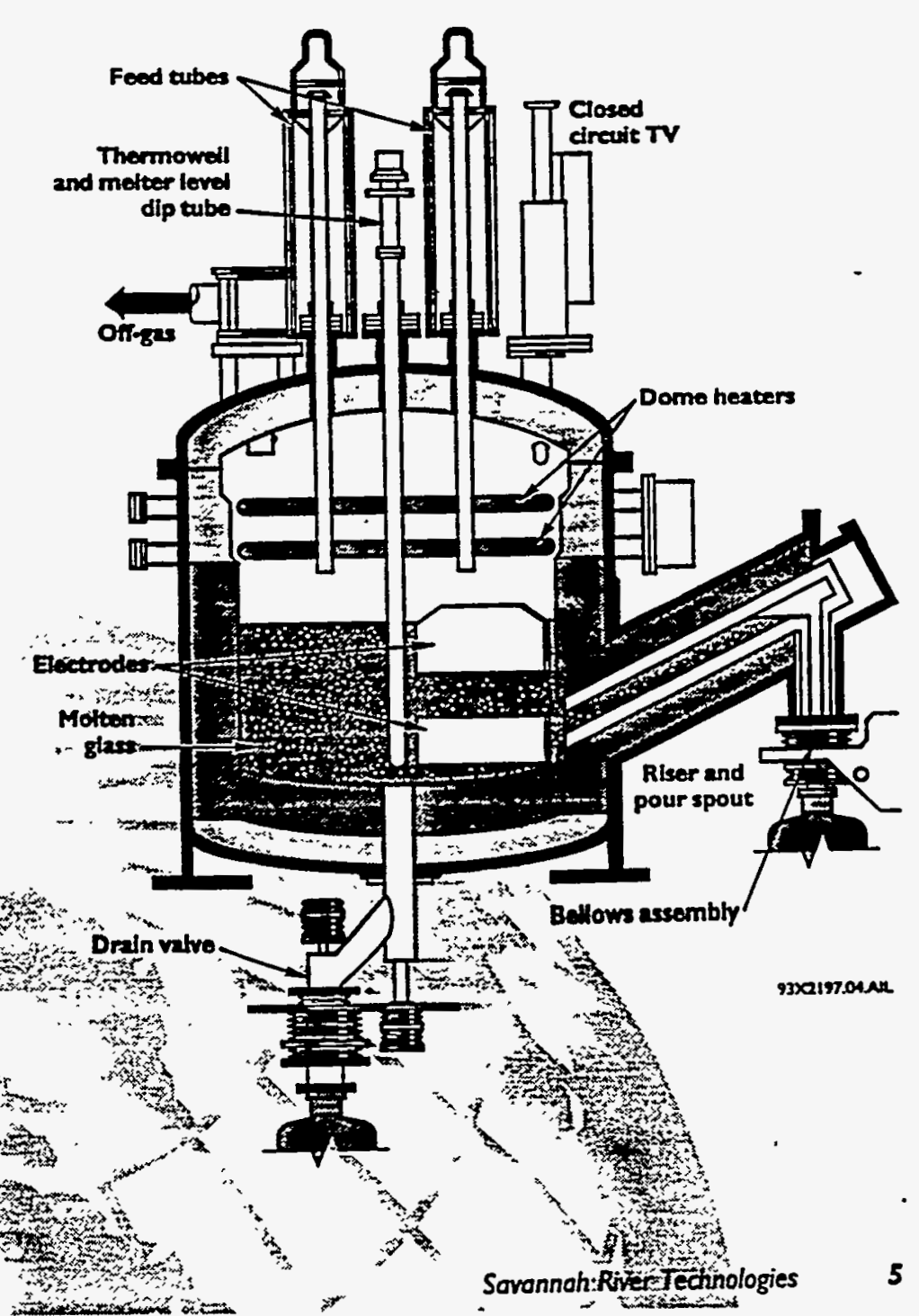




\section{Polyethylene Encapsulation Process Flow Diagram}

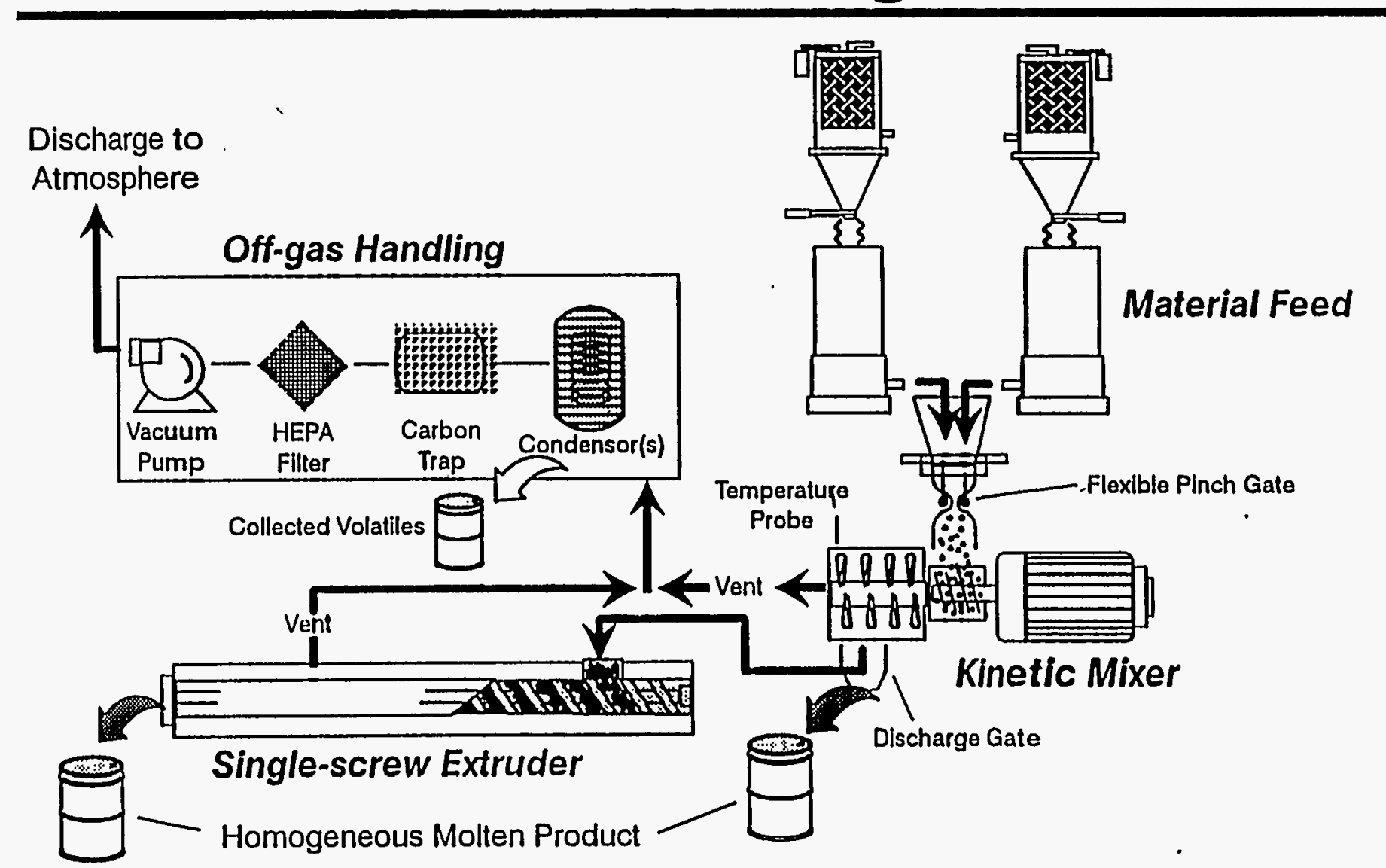




\section{Chemical Compatibility of Wastes With Sulfur Polymer}

\begin{tabular}{|l|l|}
\hline Waste Type & Waste Compatibility \\
\hline Ion Exchange Resins & Poor \\
\hline Sludges & Good \\
\hline Boric Acid & Good \\
\hline Sulfate salts & Good \\
\hline Nitrate salts & Incompatible \\
\hline Chloride salts & Good \\
\hline Carbonate salts & Good \\
\hline Organic Liquids & Poor \\
\hline Acidic Solutions & Good \\
\hline Alkaline Solutions & Poor - Fair \\
\hline Incinerator Bottom Ash & Good \\
\hline Incinerator Fly Ash & Good \\
\hline
\end{tabular}

बอपू Environmental and Waste Technology Center 


\section{Sulfur Polymer Encapsulation Process Flow Diagram}

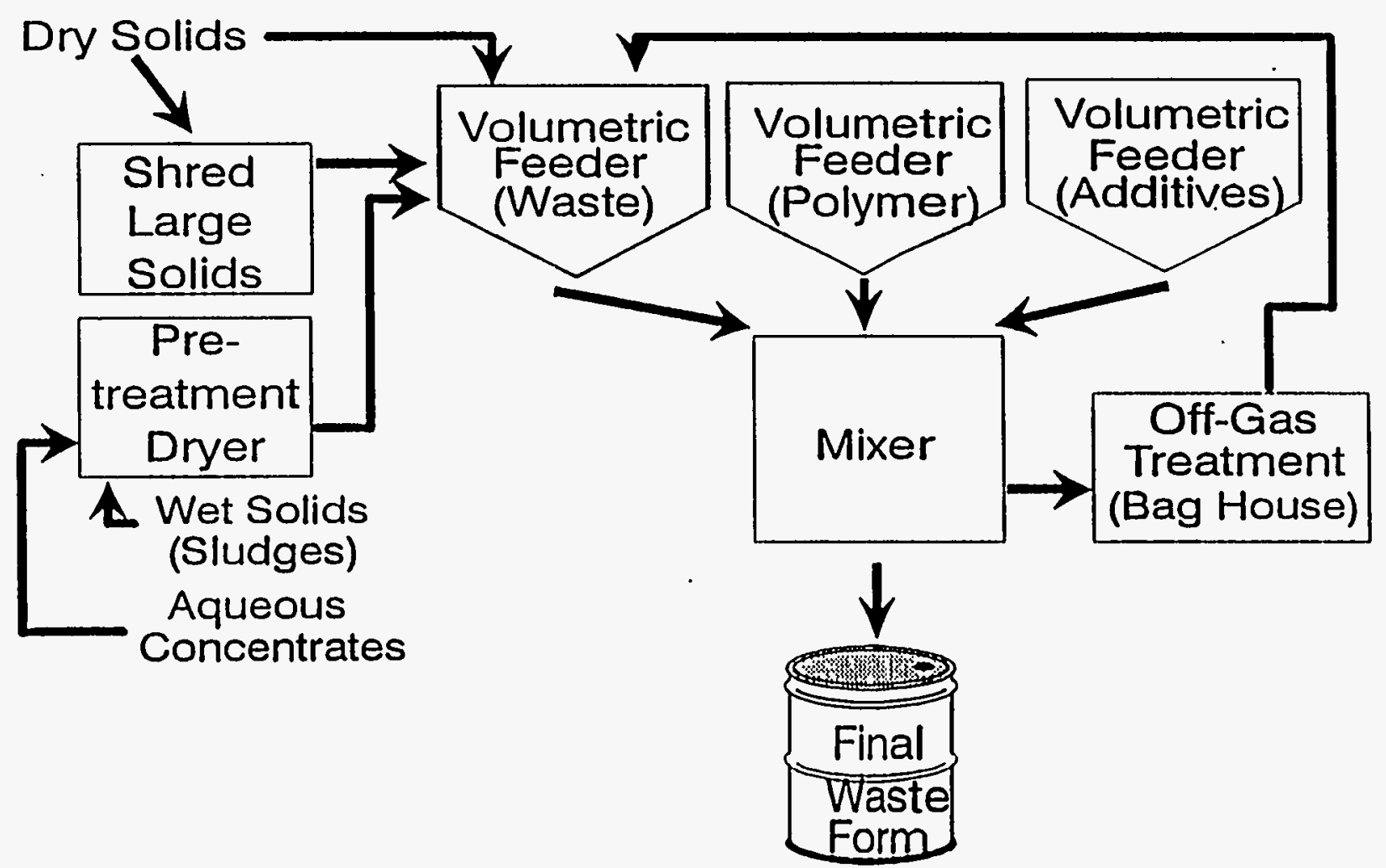


ORNL/TM-13486

\section{INTERNAL DISTRIBUTION}

1. G. E. Courville

2. S. G. Hildebrand

3. C. I. Moser

4. R. M. Reed

5. R. B. Shelton

6-20. J. W. Terry

21. G. P. Zimmerman

22. Central Research Library

23. Laboratory Records-RC

24-25. Laboratory Records for submission to OSTI

\section{EXTERNAL DISTRIBUTION}

26. Dr. Lilia A. Abron, President, PEER Consultants, P.C., 1460 Gulf Boulevard, $11^{\text {th }}$ Floor, Clearwater, Florida 34630

27. Dr. Thomas E. Drabek, Professor, Department of Sociology, University of Denver, Denver, Colorado 80208-0209

28. Mr. Earl W. McDaniel, Consultant, 724 Robertsville Road, Oak Ridge, Tennessee 37830

29. ORNL Site Manager, U.S. Department of Energy, Oak Ridge National Laboratory, Post Office Box 2008, Oak Ridge, Tennessee 37831-6269

30. Mr. P. Richard Rittelmann, FAIA, Executive Vice President, Burt Hill Kosar Rittelmann Associates, 400 Morgan Center, Butler, Pennsylvania 16001-5977

31. Mr. Michael Rivera, Rocky Flats Environmental Technology Site, B441, Post Office Box 464, Golden, Colorado 80402-0464

32. Dr. Susan F. Tierney, The Economic Resource Group, Inc., One Mifflin Place, Cambridge, Massachusetts 02138

33. Dr. C. Michael Walton, Ernest H. Cockrell Centennial Chair In Engineering and Chairman, Department of Civil Engineering, University of Texas at Austin, Austin, Texas 78712-1076 